\title{
Análise da Participação da Agropecuária no PIB do Brasil de 1986 a 2004
}

\author{
- RICARDO BRUgNaRO*
}

- Carlos josé Caetano Bacha **

\begin{abstract}
RESUMO
De acordo com a experiência internacional, a importância da agropecuária no produto interno bruto (PIB) de um país apresenta tendência declinante ao longo do tempo. Isto tem ocorrido na maioria das nações, inclusive no Brasil no período de 1960 a 1993. Porém, a partir de meados dos anos 90 até 2004, o Brasil apresentou crescimento nessa variável, o qual não foi seguido pela maioria dos países sul-americanos. Este artigo analisa os fatores que explicam a participação da agropecuária no PIB brasileiro nos anos de 1986 a 2004 e a razão de seu crescimento a partir de meados da década de 90 até 2004. A metodologia utilizada é a organização dos dados publicados em gráficos e tabelas e a análise econométrica desses dados. Um modelo contábil foi desenvolvido para explicar os principais fatores que afetam a participação da agropecuária no PIB e um modelo econométrico foi adaptado para estimar este modelo contábil. Usando dados de 1986 a 2004, nossos resultados econométricos confirmam a mudança estrutural na curva de participação da agropecuária no PIB, e as principais variáveis explicando essa participação, no período de 1993 a 2004, são a produtividade da indústria, a razão preços recebidos/ preços pagos pela agropecuária, a produtividade da agropecuária e a participação defasada da agropecuária no PIB.
\end{abstract}

\section{Palavras-Chave}

PIB, importância da agropecuária, modelo econométrico, Brasil

\begin{abstract}
According to global experience, agriculture's contribution to a country's gross domestic product (GDP) has diminished over the years. This has occurred in almost nations, including in Brazil from 1960 to 1993. However, from middle 1990's to the year of 2004, Brazil experienced an increase in this variable, what was not followed by most of the South American countries. This paper analyzes the factors that explain agriculture's contribution to the Brazilian gross domestic product during 1986-2004 period and the reasons for the rise of this contribution since mid-90s to 2004. The methodology used is both organization of published dataset in graphs and tables as well as econometric analysis of these data. An accounting model is used to explain the main factors affecting agriculture's contribution to GDP growth and an econometric model is adapted for estimating the accounting model. Using dataset from 1986 to 2004, our econometric findings confirm there is a structural change in the curve of agriculture participation in the GDP, and the main variables determining this, from 1993 to 2004, are (received/paid prices) ratio, agricultural and industrial productivities as well as lagged participation of agriculture in the GDP.
\end{abstract}

\section{KEYWORDS}

GDP, agriculture importance, econometric model, Brazil

\section{JEL CLASSIFICATION \\ QI0, AIO}

\footnotetext{
* Mestre em Economia Aplicada- ESALQ/USP. Endereço para contato: R. Sete de Setembro, 6I5, ap. 20 - Limeira - SP. E-mail: rbrugnar@yahoo.com.br.

** Professor Titular da ESALQ/USP. Endereço para contato: Av. Pádua Dias, II - Piracicaba - SP. E-mail: cjcbacha@ esalq.usp.br.

(Recebido em janeiro de 2006. Aceito para publicação em agosto de 2007).
} 


\section{INTRODUÇÃO}

A evidência mundial é que a participação da agropecuária no produto interno bruto (PIB) apresenta tendência declinante ao longo do tempo, com o consequente crescimento da importância de outros setores (indústria e serviços). No começo do século atual, países desenvolvidos - como Japão, Inglaterra e EUA - apresentam participação da agropecuária no PIB inferior a $2 \%$ e tendência, apesar das oscilações, declinante nas últimas quatro décadas. Países subdesenvolvidos como Bolívia, Colômbia e Equador também apresentam tendência declinante da participação da agropecuária no PIB (atualmente está entre 7,5\% e 15\% do PIB, segundo informações do WORLD BANK, 2005).

Poucos países, como Venezuela, apresentam oscilação da participação da agropecuária no PIB em torno de um valor médio estável durante os últimos 45 anos. Porém, no caso do Brasil, a participação da agropecuária no PIB apresentou tendência declinante até 1993 (seguindo o padrão mundial), revertendo esta situação de forma consistente a partir de meados da década de 90 até 2004. A série brasileira do PIB vigente até 2006 (que segue a revisão metodológica das contas nacionais do Brasil feita em 1997, SCN/Brasil/97) mostra a participação da agropecuária no PIB aumentando de 1994 a 2004, e neste último ano a agropecuária representou 9,6\% do PIB brasileiro (aumento de $65,5 \%$ em relação ao percentual de 1993). A nova série do PIB brasileiro, divulgada em 21/03/07 (SCN/Brasil/07), evidencia que a participação da agropecuária no PIB ficou estável nos anos de 1995 e 1996 em relação ao nível existente em 1993 e aumentou de 1998 a 2003, passando de 5,5\% a 7,4\%, respectivamente (aumento de 34,5\%), caindo para 6,9\% em 2004. Independente de qual série de dados do PIB se considera (a que se baseia na revisão metodológica das contas nacionais do Brasil de 1997 ou na de 2007), a participação da agropecuária no PIB brasileiro aumentou de meados dos anos 90 até 2004. Caso semelhante de aumento de importância da agropecuária no PIB é o argentino, cuja participação da agropecuária no PIB passou de menos de 5\% em 2001 para aproximadamente $11 \%$ nos anos de 2002 e 2003, caindo ligeiramente para 10,4\% em 2004 e 9,4\% em 2005 (WORLD BANK, 2005 e 2007).

Esse comportamento atípico do aumento da participação da agropecuária no PIB brasileiro já foi diagnosticado e analisado por Bacha e Rocha (1998), que o atribuiu a três fatores: aumento da produtividade na agropecuária, aumento da relação de preços agrícolas/ preços industriais e aumento da relação de preços recebidos/ preços pagos pela agropecuária. No entanto, a importância desses fatores não foi quantificada através de modelo econométrico e tampouco foram discutidos outros fatores que afetam a participação da agropecuária no PIB. 
O objetivo deste artigo é avaliar os fatores que determinam a participação da agropecuária no PIB do Brasil no período de 1986 a 2004, quantificando a influência desses fatores através de um modelo econométrico. Este último, ao ser estimado, restringe-se à parte do período supracitado, ou seja, aos anos de 1993 a 2004.

O presente artigo está dividido em sete seçóes, incluindo a introdução e o objetivo. A seção 3 apresenta uma revisão bibliográfica sobre a participação da agropecuária no PIB. A seção 4 apresenta as evidências mundiais sobre o comportamento da participação da agropecuária no PIB e discute as duas séries de dados brasileiros disponíveis atualmente (a que se baseia na revisão metodológica das contas nacionais do Brasil de 1997, SCN/Brasil/97, e a realizada em 2007, SCN/Brasil/07). A seção 5 expõe a metodologia e os dados utilizados no presente trabalho, e as seções 6 e 7 trazem, respectivamente, os resultados e as considerações finais.

\section{REVISÃO BIBLIOGRÁFICA}

Existem vários trabalhos que tratam a tendência declinante da participação da agropecuária no PIB total, como por exemplo, Schultz (1951), Ahumada (1967), Araújo (1975) e Stern (1994). Porém, é muito restrita a literatura que relata o crescimento da participação da agropecuária no PIB brasileiro, em que se pode citar Bacha e Rocha (1998), que relatam este crescimento a partir de 1989, comportamento não verificado após a revisão dos dados realizada pelo IBGE em 1997, quando passa a utilizar o Novo Sistema de Contas Nacionais para a mensuração do PIB. No entanto, esse aumento de participação da agropecuária no PIB se fez a partir de 1994, como mostrado por Bacha e Rocha (2001), que considera os dados de contas nacionais seguindo a revisão metodológica de 1997. Os dados revistos das contas nacionais em 2007 são analisados por Bacha (2007), o qual mostra que a participação da agropecuária no PIB brasileiro diminuiu de 1947 a 1993, mantendo-se neste último patamar nos anos de 1995 e 1996 e aumentando de 1997 a 2003, para diminuir de 2004 a 2006.

Schultz (1951) relata a tendência declinante da participação da agropecuária na composição do produto interno bruto para a Inglaterra e EUA de 1800 a 1950. Com o crescimento da renda per capita, as pessoas passam a demandar outros tipos de bens além dos alimentos, uma vez que a quantidade consumida de alimentos já está em um patamar desejado pela população que possui um nível elevado de renda (nível de renda que permita a satisfação das necessidades alimentares). Assim, como os 
outros setores da economia crescem mais que a agropecuária, esta tende a reduzir sua participação na composição do PIB. O crescimento de outros setores da economia é possibilitado pela liberação de mão-de-obra do setor agropecuário para esses setores em virtude do crescimento da produtividade do trabalho na agropecuária, proporcionado por inovações tecnológicas.

Ahumada (1967), Araújo (1975) e Araújo e Schuh (1988), ao descreverem características do processo de desenvolvimento da sociedade, relatam a ocorrência de modificações estruturais na produção e na renda, com a redução da participação do setor agropecuário na formação da renda (produto), concomitantemente ao crescimento da participação do setor industrial na composição da renda. Araújo (1975) também relata a perda da importância relativa da agropecuária como geradora de emprego em virtude do alto grau de urbanização que caracteriza o processo de desenvolvimento econômico.

Araújo (1975) ressalta que, com o desenvolvimento econômico (e o consequente crescimento da renda), aumenta a demanda por bens manufaturados e serviços especializados. Estes setores aumentam sua participação na composição da renda em detrimento da agropecuária, já que os setores secundário e terciário crescem mais rapidamente que o setor primário (no qual se inclui a agropecuária).

Syrquin ${ }^{1}$ (apud ALVES, 2000) comenta que mudanças técnicas na agricultura e/ou aumento no preço relativo do trabalho induzem à mecanização e ao uso de insumos (combustíveis, fertilizantes, bens de capital), o que faz com que se reduza o valor adicionado do setor agropecuário. Este mesmo autor revela a redução da participação da agropecuária na renda e no emprego em um estudo realizado para 97 países no período de 1950 a 1983.

Stern (1994) aponta a perda nos preços relativos (preços agropecuários/ preços industriais) como a principal causa da redução da participação da agropecuária no PIB total de um país.

Guilhoto (2004), utilizando dados cross-section e referentes a alguns anos da década de 90, também mostra que países com renda per capita mais elevada tendem a apresentar menor participação da agropecuária no PIB.

Bacha e Rocha (1998) apontam a melhora dos preços relativos agropecuários/industriais, a melhora da relação de preços recebidos/preços pagos pela agropecuária e o aumento da quantidade física produzida na agropecuária advinda do aumento da

1 SYRQUIN, M. Patterns of structural change. In: CHENERY, H.; SRINIVASAN, T.N. Handbook of development economics. Amsterdan: Elsevier Science Publishers, 1988. v. 1. Chapter 7, p. 203- 273. 
produtividade como responsáveis pelo aumento da participação da agropecuária na composição do PIB brasileiro nos anos mais recentes à data do trabalho.

Barros (1999) relata que o crescimento da produção agropecuária nos últimos anos é devido, principalmente, aos ganhos de produtividade dos fatores produtivos (proporcionados pelas inovações tecnológicas) e ao crescimento do estoque de capital (principalmente de tratores) e do uso de insumos promovidos pelo grande investimento realizado na agropecuária brasileira até 1986, tanto na forma de pesquisa e extensão rural como na concessão de crédito rural subsidiado. Este crescimento de produtividade é confirmado por Gasques et al. (2004), que evidenciam o grande crescimento da produtividade total dos fatores (PTF) a partir de 1994, calculada através do índice de Tornquist.

Bonelli (2005) relata que o crescimento da participação da agropecuária no PIB do Brasil é reflexo dos elevados ganhos de produtividade que o setor apresenta desde o início da década de 1990. Bonelli (2001) ressalta, também, que o fraco desempenho do setor industrial no que diz respeito à produtividade total dos fatores (PTF), neste mesmo período, contribui para o crescimento da participação da agropecuária no PIB. Rossi Júnior e Ferreira (1999) calcularam decréscimo na PTF industrial para o período de 1985 a 1990, e reduzido crescimento para o período de 1990 a 1997, confirmando a tendência apresentada por Bonelli (2001).

Regunaga (2004) diz que o crescimento da participação da agropecuária no PIB argentino é reflexo principalmente da política interna. O autor cita que grande parte deste crescimento é oriunda da introdução de produtos geneticamente modificados que possibilitam reduzir custos e, dessa forma, aumentar a renda gerada no setor.

O agronegócio, tradução do termo inglês agribusiness, refere-se ao conjunto de atividades vinculadas com a agropecuária, incluindo a atividade agropecuária e outros três segmentos: o segmento de insumos para a agropecuária, o segmento de processamento de produtos agropecuários e segmento de distribuição dos produtos agropecuários (BACHA, 2004). Embora o processo de desenvolvimento baseado no modelo urbano-industrial leve à redução da importância da agropecuária na economia, segundo Furtuoso e Guilhoto (2003) e Guilhoto (2004), o agronegócio ganha importância econômica ao ampliar os segmentos de insumos, de processamento e de logística de distribuição e armazenamento dos produtos agropecuários, verificando que a agropecuária dinamiza o processo de produção econômica.

Observa-se, do exame da literatura acima, que algumas variáveis são ressaltadas para explicar a participação da agropecuária no PIB, em especial no Brasil. No entanto, nenhum trabalho elaborou e estimou um modelo econométrico para quantificar a 
importância das variáveis ressaltadas na determinação da participação da agropecuária no PIB.

4 AS EVIDÊNCIAS MUNDIAIS SOBRE O COMPORTAMENTO DA PARTICIPAÇÃO DA AGROPECUÁRIA NO PIB

Como relatado anteriormente, há vários grupos de países quanto à tendência da participação da agropecuária no PIB total. Pode-se citar o grupo dos países que apresentam tendência decrescente da participação da agropecuária no PIB total, que é o caso da maioria dos países. O Gráfico 1 mostra os casos do Japão, Reino Unido e EUA, e o Gráfico 2 os casos da Bolívia, Colômbia e Equador.

GRÁFICO I - PARTICIPAÇÃO DA AGROPECUÁRIA NO PIB DO JAPÃO, DO REINO UNIDO E DOS EUA -1960 A 2004

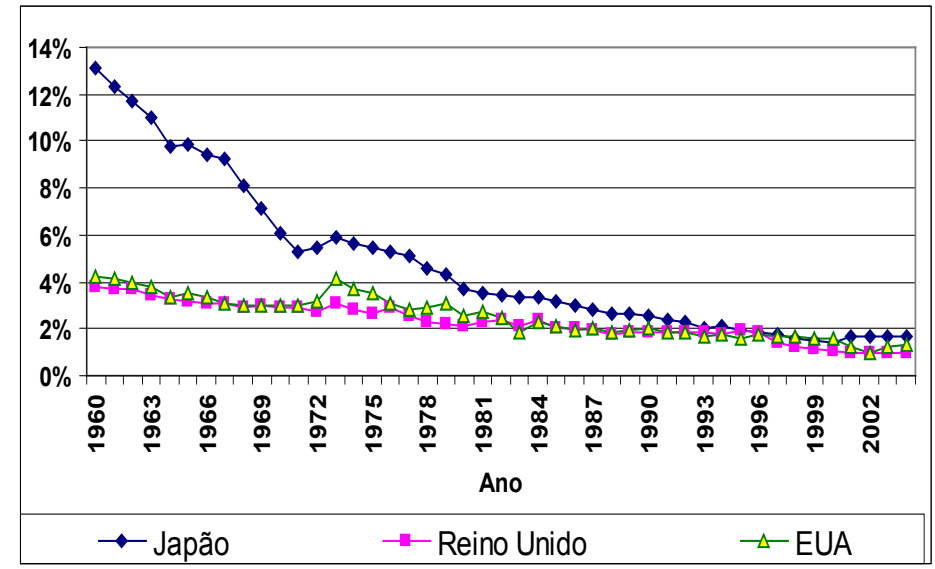

Fonte: World Bank $(2000,2005,2007)$. 
GRÁFICO 2 - PARTICIPAÇÃO DA AGROPECUÁRIA NO PIB DA BOLÍVIA, DA COLOMBIA E DO EQUADOR -1960 A 2005

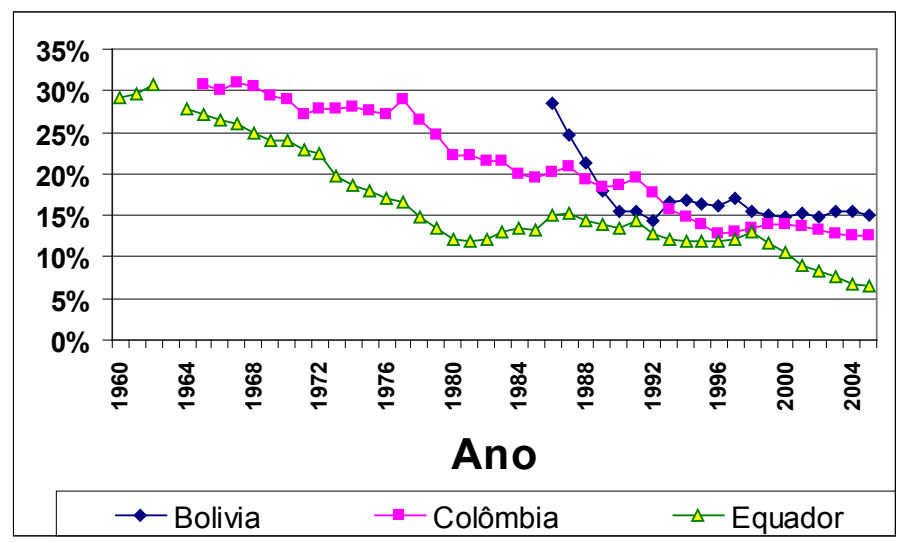

Fonte: World Bank (2000, 2005, 2007).

Países como a Venezuela apresentam certa oscilação da participação da agropecuária no PIB total, porém, com tendência de estabilidade (este comportamento pode ser verificado no Gráfico 3). A Argentina (Gráfico 3) e o Brasil (Gráfico 4) apresentam um comportamento atípico, com tendência de crescimento dessa participação no período mais recente. O Brasil inicia este comportamento ascendente em meados da década de 90 até 2004, e a Argentina em 2001.

GRÁFICO 3 - PARTICIPAÇÃO DA AGROPECUÁRIA NO PIB DA ARGENTINA E DA VENEZUELA -1960 A 2005

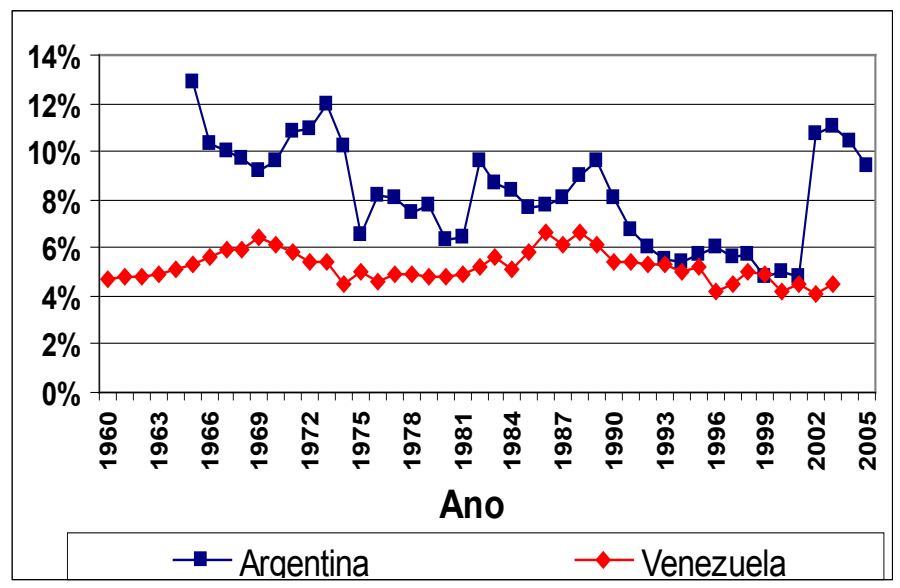

Fonte: World Bank (2000, 2005, 2007). 


\section{GRÁFICO 4 - PARTICIPAÇÃO DA AGROPECUÁRIA NO PIB DO BRASIL} -1960 A 2005

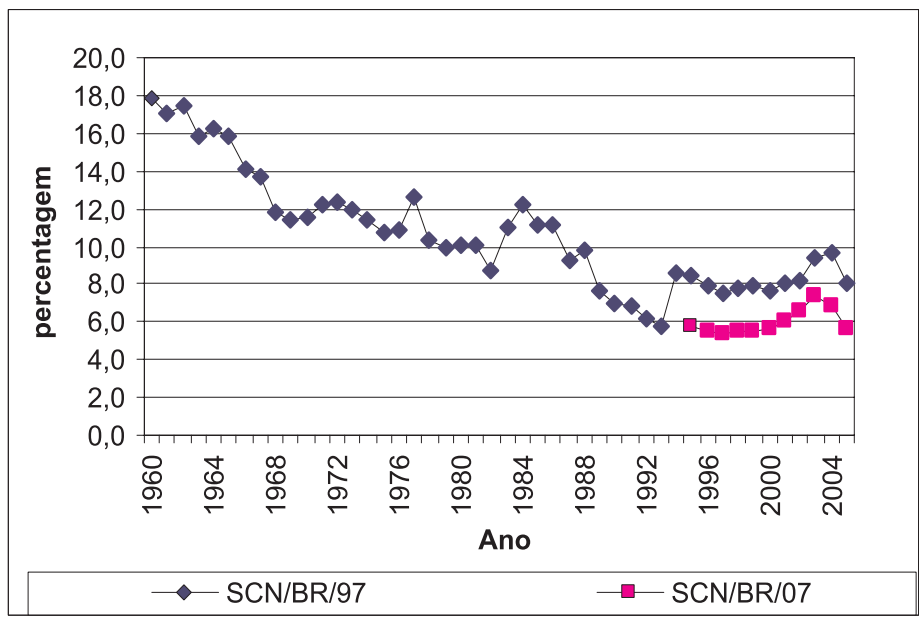

Fonte: IBGE (2005), World Bank (2005) e Bacha (2007).

A tendência de crescimento da participação da agropecuária na composição do PIB do Brasil foi primeiramente analisada por Bacha e Rocha (1998). Usando dados oficiais do Brasil, seguindo a metodologia do SCN/Brasil/85 (início dos trabalhos do IBGE nessa área), estes autores destacaram o aumento da contribuição da agropecuária para o PIB brasileiro no período de 1989 a 1996. Posteriormente, o IBGE adotou o novo sistema de contabilidade nacional elaborado pela Organização das Nações Unidas - ONU, versão 1993, revisando os valores do PIB e suas composições (veja a série SCN/Brasil/97 no Gráfico 4). De acordo com os dados do PIB, a agropecuária aumentou sua contribuição ao PIB total no período de 1994 a 2004. Essa situação também foi enfatizada por vários autores, como Bacha e Rocha (2001) e Bonelli (2005). Em março de 2007, o IBGE ampliou a base de dados utilizados no cálculo do PIB, calculando novos valores para o PIB no período de 2000 a 2006 e fazendo uma retropolação para os dados de 1995 a 1999. Segundo Bacha (2007, p. 17 e 18): "A nova série de valores do PIB para 1995 a 2006 mostra valores maiores em relação à série anterior (...) e diminuiu a importância da agropecuária e da indústria, aumentando a importância do setor serviços na composição do PIB”. Essa diminuição da importância da agropecuária no PIB é mostrada no Gráfico 4, na qual a linha da série SCN/Brasil/07 está abaixo da série SCN/Brasil/97. No entanto, o IBGE não reviu a informação de 1994, o que dificulta comparar a série SCN/Brasil/07 da participação da agropecuária no PIB com a existente até 1993, o que não ocorre ao se utilizar a série SCN/Brasil/97. 
Diante dessa situação, o presente artigo estima suas equações considerando, primeiramente, a série de dados sobre a participação da agropecuária no PIB do SCN/ Brasil/97 e, em seguida, verifica as mudanças nas estimativas que ocorrem ao se utilizar o valor dessa participação calculado pelo SCN/Brasil/07.

\section{METODOLOGLA E DADOS UTILIZADOS}

Esta seção destina-se a apresentar o modelo de determinação da participação da agropecuária no PIB e os dados utilizados para a caracterização da agropecuária brasileira e para a estimação econométrica desse modelo.

\subsection{Modelo de Determinação da Participação do Setor Agropecuário no PIB}

Esta seção expõe o modelo contábil de Bacha e Rocha (1998) sobre a determinação da participação da agropecuária no PIB, derivando, a partir dele, um modelo econométrico e discutindo os dados viáveis para estimá-lo.

Bacha e Rocha (1998) definiram as seguintes variáveis:

$V A_{A}=$ valor adicionado pelo setor agropecuário;

$V A_{I}=$ valor adicionado pelo setor não-agropecuário;

$P_{A}=$ preço médio dos produtos do setor agropecuário;

$P_{I}=$ preço médio dos bens e serviços do setor não-agropecuário;

$P_{A}{ }^{I}=$ preço médio dos produtos agropecuários usados como insumos no setor nãoagropecuário;

$P_{I}^{A}=$ preço médio dos bens e serviços não-agropecuários usados como insumos no setor agropecuário;

$I_{I}^{A}=$ quantidade física de insumos não-agropecuários usados no setor agropecuário;

$I_{A}{ }^{A}=$ quantidade física de insumos agropecuários usados no setor agropecuário;

$I_{I}^{I}=$ quantidade física de insumos não-agropecuários usados no setor nãoagropecuário;

$I_{A}{ }^{I}=$ quantidade física de insumos agropecuários usados no setor nãoagropecuário;

$Q_{A}=$ quantidade física produzida no setor agropecuário;

$Q_{I}=$ quantidade física produzida no setor não-agropecuário. 
Portanto, o subscrito é o setor que produz e o sobrescrito é o setor que utiliza. $A$ é setor agropecuário e $I$ é o setor não-agropecuário.

O modelo de Bacha e Rocha (1998) tem quatro equações básicas, que são:

$P_{a g r}=\frac{V A_{A}}{V A_{I}+V A_{A}} \quad$ ou $\quad P_{a g r}=\frac{1}{1+\frac{V A_{I}}{V A_{A}}}$

onde:

$P_{a g r}$ é a participação da agropecuária no PIB.

Da equação (1) tem-se que o aumento de $\frac{V A_{A}}{V A_{I}}$ faz aumentar $P_{a g r}$.

Para determinar as variáveis que afetam $\frac{V A_{A}}{V A_{I}}$, considere que:

$$
\begin{aligned}
& V A_{A}=P_{A} \cdot Q_{A}-P_{A} \cdot I_{A}^{A}-P_{I}^{A} \cdot I_{I}^{A} \\
& V A_{I}=P_{I} \cdot Q_{I}-P_{A}{ }^{I} \cdot I_{A}^{I}-P_{I} \cdot I_{I}^{I}
\end{aligned}
$$

Dividindo (2) por (3) e dividindo o numerador e o denominador por $P_{A}$, além de proceder a ajustes matemáticos, tem-se:

$$
\frac{V A_{A}}{V A_{I}}=\frac{\left(Q_{A}-I_{A}^{A}\right)-\frac{P_{I}^{A}}{P_{A}} \cdot I_{I}^{A}}{\frac{P_{I}}{P_{A}} \cdot\left(Q_{I}-I_{I}^{I}\right)-\frac{P_{A}^{I}}{P_{A}} \cdot I_{A}^{I}}
$$

A expressão (4), em seu numerador, revela que um aumento na produtividade física do setor agropecuário [aumento de $\left(Q_{A}-I_{A}^{A}\right)$ ], em condições coeteris paribus, leva ao aumento de $\frac{V A_{A}}{V A_{I}}$, o que, pela expressão (1), leva ao aumento da participação do setor agropecuário no PIB. Ainda em seu numerador, a expressão (4) mostra que um aumento de $\frac{P_{A}}{P_{I}^{A}}$ (indicador do valor adicionado unitário no setor agropecuário), 
em condições coeteris paribus, eleva $\frac{V A_{A}}{V A_{I}}$, gerando um aumento da participação do setor agrope-cuário no PIB.

A expressão (4), em seu denominador, coloca que a redução de $\frac{P_{I}}{P_{A}}$, ou o aumento de $\frac{P_{A}}{P_{I}}$ (relação de preços agropecuários e não-agropecuários), em condições coeteris paribus, aumenta $\frac{V A_{A}}{V A_{I}}$, o que também eleva a participação do setor agropecuário no PIB.

Os três elementos acima evidenciados foram ressaltados por Bacha e Rocha (1998). Cabe ressaltar, também, que o aumento da produtividade industrial [aumento de $\left.\left(Q_{I}-I_{I}^{I}\right)\right]$, em condições coeteris paribus, reduz a relação $\frac{V A_{A}}{V A_{I}}$, reduzindo a participação da agropecuária no PIB. Essas conclusões permitem estimar a equação (4) através da seguinte fórmula:

$$
P_{a g r}=\frac{V A_{A}}{V A_{I}+V A_{A}}=f\left[\left(Q_{A}-I_{A}^{A}\right) \frac{P_{A}}{P_{I}}, \frac{P_{I}^{A}}{P_{A}},\left(Q_{I}-I_{I}^{I}\right)\right]
$$

sendo que

$$
\begin{aligned}
& \left(Q_{A}-I_{A}^{A}\right) \uparrow \Rightarrow P_{a g r} \uparrow ; \\
& \left(Q_{I}-I_{I}^{I}\right) \uparrow \Rightarrow P_{a g r} \downarrow ; \mathrm{e} \\
& \frac{P_{A}}{P_{I}} \uparrow \Rightarrow P_{a g r} \uparrow .
\end{aligned}
$$

\subsection{Dados Utilizados}

Para estimar a equação (5) são utilizados dados secundários. Os dados de participação do setor agropecuário no PIB total são do IBGE. Inicialmente, considera-se a série de $P_{\text {agr }}$ obtida com o SCN/Brasil/97 para definir o melhor modelo econométrico e, em seguida, observam-se mudanças que ocorrem ao se trocar $P_{a g r}$ pela nova série definida pelo $\mathrm{SCN} /$ Brasil/07. Os preços $P_{A}, P_{I}$ e $P_{I}^{A}$ são considerados na forma de índices de preços e são oriundos da Fundação Getulio Vargas. As produtividades 
também são mensuradas na forma de índices. São consideradas duas definições alternativas de produtividade: produtividade total dos fatores e a produtividade do trabalho para o setor agropecuário e para o setor industrial (este último como representativo do setor não-agropecuário). $\mathrm{O}$ índice de produtividade total dos fatores no setor agropecuário é de Gasques et al. (2004) e o índice de produtividade total dos fatores na indústria é de Bonelli (2001) e de informações pessoais cedidas por Regis Bonelli. Os dados da produtividade do trabalho na agropecuária são de Gasques et al. (2004) e os dados da produtividade do trabalho no setor industrial são do IBGE, consultados pelo Sistema SIDRA.

Os índices de preços apresentados são: (1) preços recebidos / preços pagos pelos agricultores do Estado de São Paulo e (2) preços agropecuários / preços industriais para todo o Brasil, ambos publicados pela Fundação Getulio Vargas - FGV.

Para caracterização da agropecuária brasileira foram apresentados dados referentes a emprego, produção, produtividades agrícolas e pecuárias e área plantada publicados pelo IBGE, consultados através do Sistema SIDRA e em vários números do Anuário Estatístico do Brasil. Os dados da produtividade do trabalho na agropecuária são de Gasques et al. (2004). Para comparação, foram apresentados os dados da produtividade do trabalho no setor industrial publicados pelo IBGE.

\section{RESULTADOS}

Esta seção analisa, através de gráficos, o comportamento de algumas variáveis que determinam o valor do produto interno bruto da agropecuária e/ou sua participação no PIB total do Brasil. Essas variáveis foram definidas a partir da literatura consultada e com base no modelo de Bacha e Rocha (1998). Essas variáveis são analisadas para o período de 1986 a $2004^{2}$, período em que a agropecuária cresceu sem grandes subsídios governamentais. Em seguida, o modelo econométrico definido no item 5.1, na equação (5), é estimado de várias formas para determinar a importância das variáveis selecionadas na determinação da participação da agropecuária no PIB.

2 Algumas variáveis serão avaliadas de 1986 a 2002/2003 em função da disponibilidade de dados. 


\subsection{Preços Relativos}

- Preços Agropecuários Versus Preços Industriais

Analisando o Gráfico 5, percebe-se que desde 1993, excetuando-se certas oscilações, a relação de preços agropecuários/ preços industriais (preços industriais como proxy de preços não-agropecuários) é crescente (exceto 2004), ou seja, favorável ao crescimento da participação da agropecuária no PIB. No período de janeiro de 1993 a

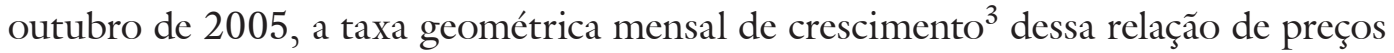
foi de $0,0134 \%$.

A tendência crescente da relação de preços agropecuários/ preços industriais de 1994 a 2004 foi causada por: ${ }^{4}$ (1) elevação do preço internacional de importantes commodities exportadas pelo Brasil, como por exemplo a soja; (2) redução das tarifas de importação de produtos industrializados (o que reduz seu preço final); (3) redução das barreiras de importação de bens industrializados; e (4) forte valorização cambial até 1998 (a qual reduziu os preços dos produtos industrializados). Estes fenômenos geraram um crescimento mais acelerado da receita da agropecuária se comparado ao setor não-agropecuário.

GRÁFICO 5 - EVOLUÇÃO DA RELAÇÃO DOS ÍNDICES DE PREÇOS AGROPECUÁRIOS/ PREÇOS INDUSTRIAIS NO BRASIL (BASE $100=$ AGOSTO DE 1994)

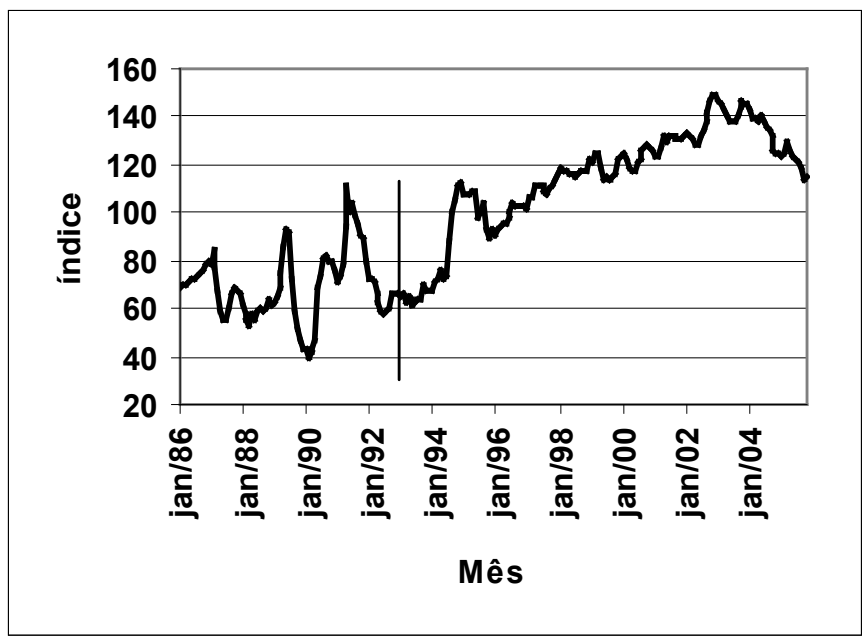

Fonte: FGV (2005).

3 A taxa geométrica de crescimento é definida como: $T G C=e^{b}-1$, onde $b$ é o coeficiente da regressão $Y=a+b \ln t$ (em que $Y$ é a variável avaliada e $t$ é o tempo).

4 Itens 2,3 e 4 foram analisados por Baer (2001). 


\section{- Preços Recebidos Versus Preços Pagos}

O Gráfico 6 revela que houve grande aumento na relação preços recebidos/ preços pagos na agropecuária paulista (essa relação como proxy da relação para toda a agropecuária brasileira $^{5}$ ) em 1993 e 1994, com diminuição em 1995 e tendência de crescimento desde 1996. O valor médio dessa relação a partir de 1996 é superior ao existente de 1988 a 1992. A taxa geométrica de crescimento mensal da relação preços recebidos/ preços pagos na agropecuária paulista de janeiro de 1993 a dezembro de 2004 foi de $0,0045 \%$. Isto se deve parcialmente ao aumento da relação de preços agropecuários/ preços industriais. A relação entre as razões de preços recebidos/ preços pagos e preços agropecuários/ preços industriais deve ser considerada quando da estimação da equação (5), uma vez que pode ocorrer multicolinearidade entre as variáveis explicativas.

GR ÁFICO 6 - EVOLUÇÃO DA RELAÇÃO DOS ÍNDICES DE PRECOS RECEBIDOS/ PREÇOS PAGOS PELA AGROPECUÁRIA PAULISTA (BASE $100=$ AGOSTO DE 1994)

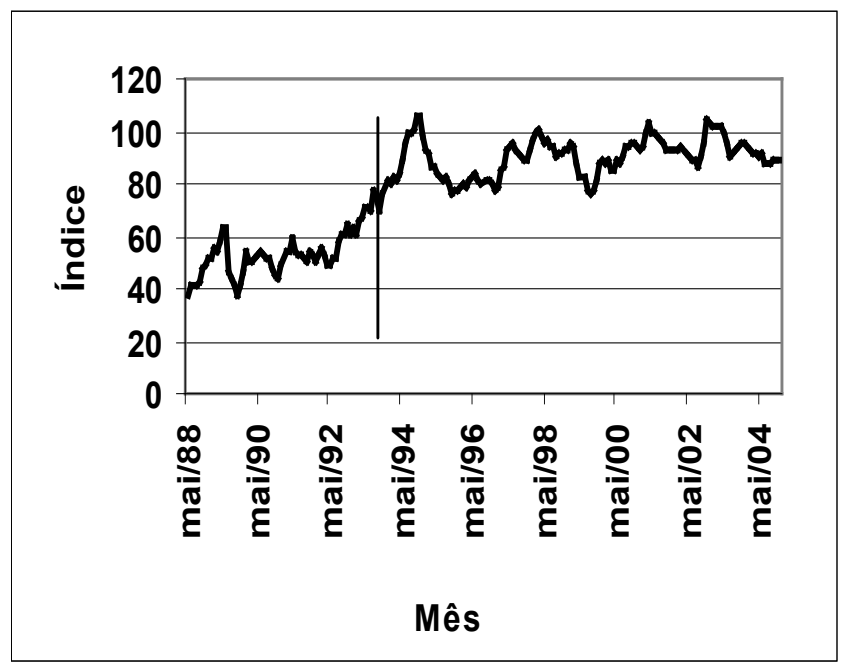

Fonte: FGV (2005).

5 Em virtude de o Estado de São Paulo balizar os preços dos produtos agropecuários (recebido pelos produtores) e ser o principal Estado produtor dos insumos industrializados utilizados na atividade agropecuária. 


\subsection{Quantidade Produzida e Índices de Produtividade da Agropecuária}

- Produção Agrícola

A produção agrícola brasileira, avaliada para 38 principais culturas ${ }^{6}$, apresentou crescimento de 1986 a 2004, passando de 343 milhões de toneladas para 601 milhões de toneladas, respectivamente (Gráfico 7). Verifica-se que o maior crescimento ocorreu de 1993 a 2004, período que apresenta taxa geométrica de crescimento de 3,7\% a.a., bastante superior ao crescimento no período de 1986 a 1993, que apresentou taxa geométrica de crescimento de $0,7 \%$ a.a. (crescimento avaliado para as 38 principais culturas do Brasil). A produção de soja cresceu a uma taxa geométrica de 7,9\% a.a. no período de 1993 a 2004, atingindo quase 50 milhôes de toneladas no final do período. Esse crescimento da produção contribuiu para o crescimento da participação da agropecuária no PIB do Brasil.

\section{GRÁFICO 7 - EVOLUÇÃO DA PRODUÇÃO AGRÍCOLA BRASILEIRA - 1986 A 2004}

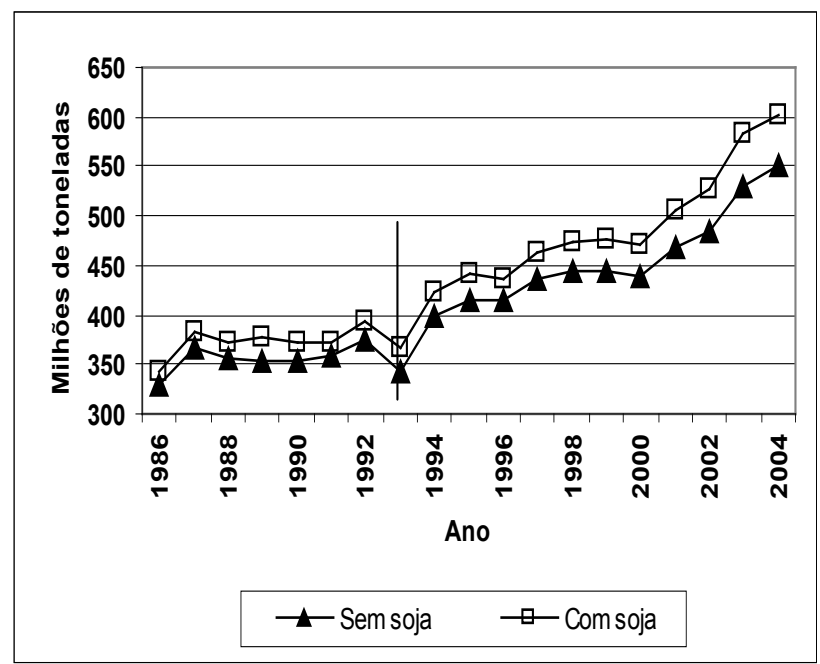

Fonte: IBGE (1987-1989, 1991-1993, 2003, 2005).

O crescimento da produção agrícola brasileira no período de 1986 a 1993 ocorreu com redução de área e crescimento da produtividade. A área colhida passou de 52,5 milhões de hectares em 1986 para 45,7 milhões de hectares em 1993. A produtividade passou de aproximadamente $6.500 \mathrm{~kg} / \mathrm{ha}$ em 1986 para aproximadamente

6 Abacate, algodão arbóreo, algodão herbáceo, alho, amendoim, arroz, aveia, batata, cacau, café, cana-deaçúcar, castanha, cebola, centeio, cevada, coco, feijão, fumo, goiaba, guaraná, juta, laranja, limão, maçã, malva, mamona, mandioca, manga, maracujá, milho, pimenta-do-reino, sisal, soja, sorgo, tangerina, tomate, trigo e uva. 
$8.000 \mathrm{~kg} / \mathrm{ha}$ em 1993 (considerando as 38 principais culturas do Brasil). Estes números revelam redução de $1,9 \%$ a.a. da área colhida com as 38 principais culturas brasileiras e crescimento de 2,63\% a.a. da produtividade. No período de 1993 a 2004, a produção cresceu devido ao crescimento da área colhida (taxa geométrica de crescimento de $1,84 \%$ a.a.) e ao crescimento de produtividade (taxa geométrica de crescimento de $1,82 \%$ a.a.). O crescimento em área foi intenso e com tendência irreversível a partir de 1996. Em 2004, a área colhida com as 38 principais culturas do País foi de 60,9 milhões de hectares, com produtividade de quase $10.000 \mathrm{~kg} / \mathrm{ha}$. Essa evolução pode ser verificada no Gráfico 8.

A maior parte do crescimento em área da agricultura brasileira a partir de 1996 foi atribuída à soja. Se excluirmos a soja da análise, ou seja, avaliando a agricultura brasileira para as 37 principais culturas, o crescimento em área ocorre apenas a partir de 1998, como pode ser verificado no Gráfico 9. Para o período de 1993 a 2004, o crescimento em área das 37 principais culturas do País foi de apenas 0,3\% a.a., enquanto o crescimento da área colhida com soja foi de 5,9\% a.a. no mesmo período. A soja expandiu seu cultivo em 8,6 milhões de hectares de 1999 para 2004 (passando de 13 milhões para 21,6 milhões de hectares, respectivamente).

\section{GRÁFICO 8 - EVOLUÇÃO DA ÁREA COLHIDA E DA PRODUTIVIDADE AGRÍCOLA DO BRASIL - 38 PRINCIPAIS CULTURAS - 1986 A 2004}

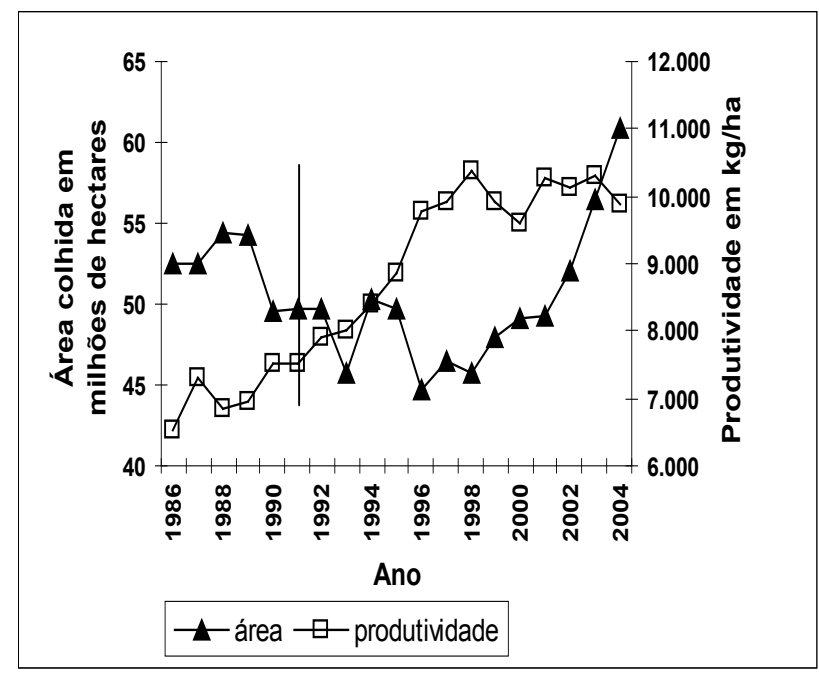

Fonte: IBGE (1987-1989, 1991-1993, 2003, 2005). 


\section{GRÁFICO 9 - EVOLUÇÃO DA ÁREA COLHIDA E DA PRODUTIVIDADE AGRÍCOLA DO BRASIL - 37 PRINCIPAIS CULTURAS - 1986 A 2004}

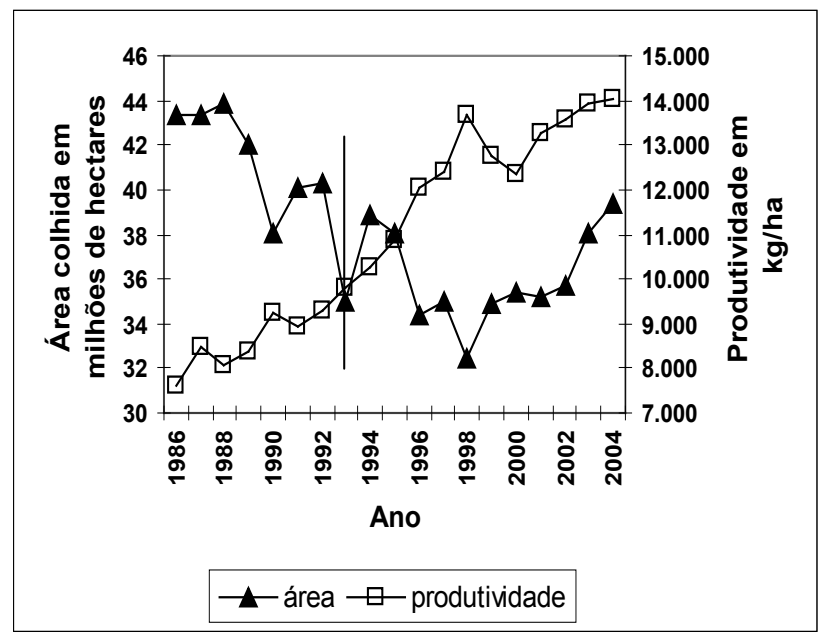

Fonte: IBGE (1987-1989, 1991-1993, 2003, 2005).

\section{- Produção de Carnes}

Analisando a produção brasileira de carnes, ${ }^{7}$ percebe-se um crescimento sem interrupção no período de 1986 a 2002 (Gráfico 10), passando de 3,76 milhões de toneladas em 1986 para 12,65 milhões de toneladas em 2002, contribuindo para o aumento da participação da agropecuária no PIB brasileiro. A produção de carnes apresentou taxa de crescimento geométrica de 6,8\% a.a. de 1986 a 1993 e de 7,8\% a.a. de 1993 a 2002, com destaque para a produção de carne de aves, que apresentou taxa de crescimento de $8,4 \%$ a.a. e de $12,7 \%$ a.a., respectivamente, para os períodos de 1986 a 1993 e de 1993 a 2004. Este crescimento atribui à produção de carnes um desempenho superior ao agrícola no mesmo período, como já destacaram Furtuoso e Guilhoto (2003).

Esse expressivo crescimento da produção de carnes deve-se, em parte, ao crescimento do rendimento de carcaça por animal e, também, ao crescimento do número de animais abatidos no período de 1986 a 2004.

7 Carnes bovina, suína e de aves. 
GRÁFICO 10 - EVOLUÇÃO DA PRODUÇÃO BRASILEIRA DE CARNES - 1986 A 2002

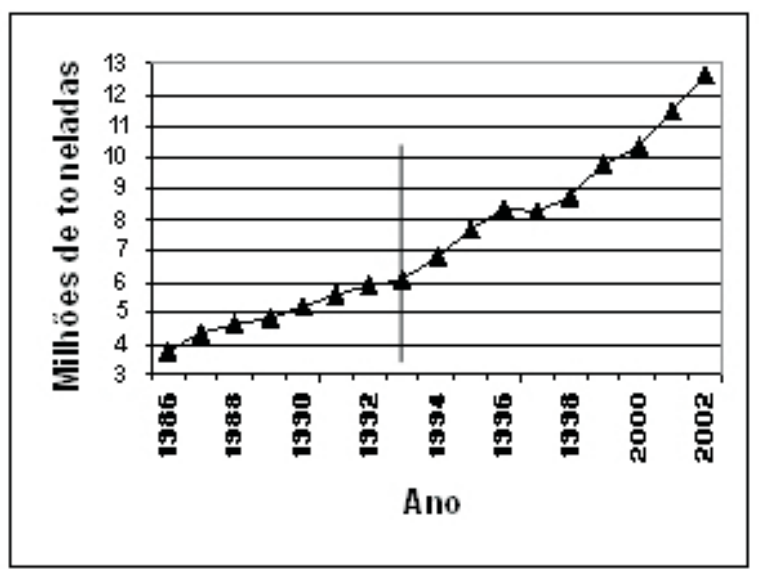

Fonte: IBGE (1987-1989, 1991-1993, 2003, 2005).

O Gráfico 11 mostra o crescimento do rendimento de kg de carcaça por animal abatido para os três grupos de animais (bovinos, suínos e de aves). Para o período de 1986 a 1993, a produção de carne bovina por animal abatido apresentou redução de $0,22 \%$ a.a., enquanto as produçóes de carnes suína e de aves por animal abatido apresentaram taxas geométricas de crescimento de, respectivamente, $0,13 \%$ a.a. e $1,15 \%$ a.a. (em rendimento de carcaça). No período de 1993 a 2002, todos os tipos de pecuária apresentaram taxas geométricas de crescimento positivas para rendimento de carcaça ( $1,33 \%$ a.a., $0,93 \%$ a.a. e $0,86 \%$ a.a., respectivamente, para bovinos, suínos e aves).

\section{GRÁFICO 11 - ÍNDICE DE RENDIMENTO DE CARCAÇA (KG DE CARCAÇA POR ANIMAL ABATIDO) - 1986 A $2002(B A S E 100=1986)$}

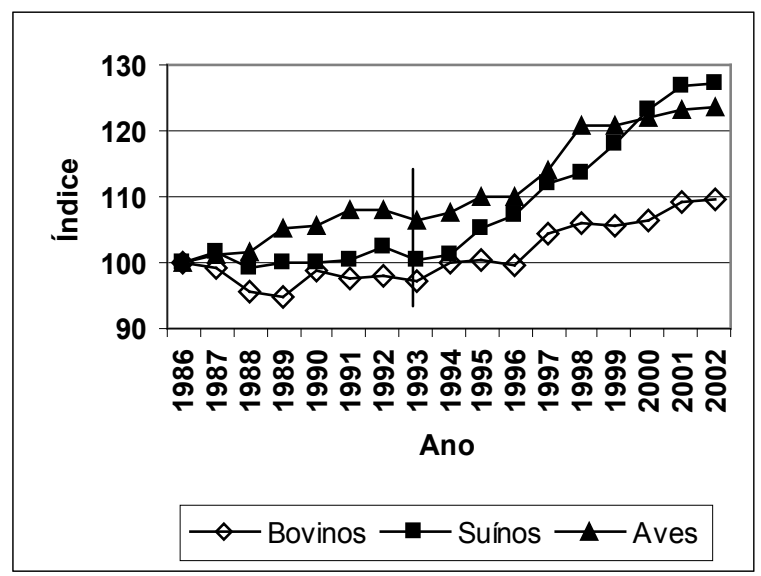

Fonte: IBGE (1987-1989, 1991-1993, 2003, 2005). 
Quanto ao número de animais abatidos (Gráfico 12), no período de 1986 a 1993 , os bovinos, suínos e aves apresentaram taxa geométrica de crescimento de, respectivamente, 6,6\% a.a., 4,9\% a.a. e 7,1\% a.a.. Para o período de 1993 a 2004, essas taxas passaram a ser, respectivamente, $3,8 \%$ a.a., $4,4 \%$ a.a. e $9,7 \%$ a.a., revelando grande expansão do número de aves abatidas. Para se ter uma idéia, 1,23 bilhão de aves foram abatidas em 1993, número que sobe para 3,55 bilhões em 2004.

Este grande crescimento no abate de animais é devido ao aumento da demanda interna e, principalmente, à conquista de novos mercados para a carne brasileira no atual século.

GRÁFICO 12 - ÍNDICE DO NÚMERO DE ANIMAIS ABATIDOS NO BRASIL - 1986 A $2004(B A S E 100=1986)$

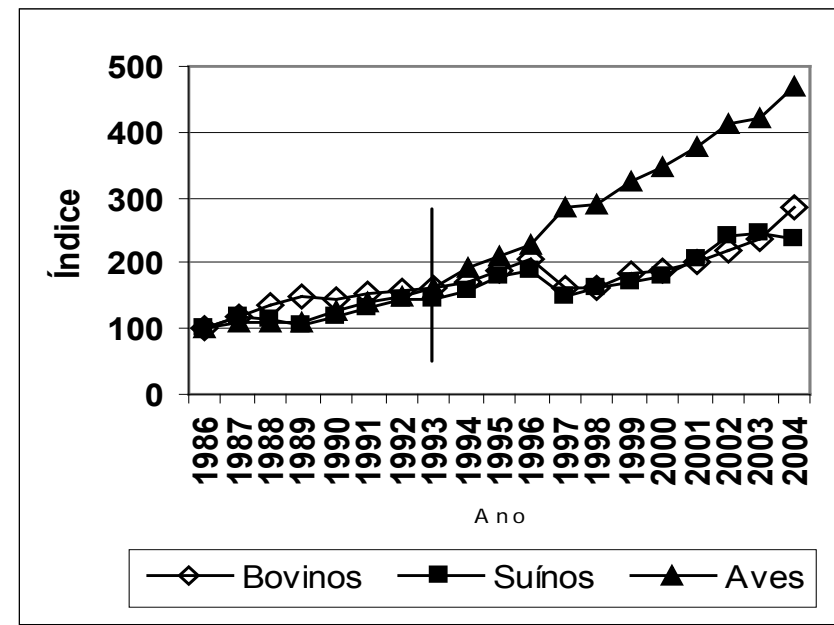

Fonte: IBGE (1987-1989, 1991-1993, 2003, 2005).

- Produtividade Total dos Fatores, do Trabalbo e Participação da Agropecuária no Emprego

O trabalho apresentou nas seções anteriores alguns indicadores de produtividade para a agricultura e pecuária separadamente. Esta seção apresenta a produtividade total dos fatores (PTF - terra, trabalho e capital) e do trabalho para toda a agropecuária brasileira.

Gasques et al. (2004) mostram que a produtividade total dos fatores calculada pelo índice de Tornqvist cresceu em todo o período de 1986 a 2002, como pode ser verificado na Gráfico 13. No período entre 1986 e 1993, este crescimento foi de 
1,78\% a.a., enquanto no período de 1993 a 2002 foi de 5,31\% a.a. (taxa geométrica de crescimento).

Embora a agropecuária tenha aumentado sua participação no PIB brasileiro, sua participação no emprego total brasileiro tem apresentado redução (Gráfico 14). Porém, sua participação no emprego ainda é superior à sua contribuição para a composição do PIB. A agropecuária representou em 2003 quase 19\% do emprego e 9,4\% do PIB (segundo a série obtida pela metodologia do SCN/Brasil/97).

GRÁFICO 13 - EVOLUÇÃO DA PRODUTIVIDADE TOTAL DOS FATORES NA AGROPECUÁRIA BRASILEIRA - 1986 A $2002($ BASE $100=1986)$

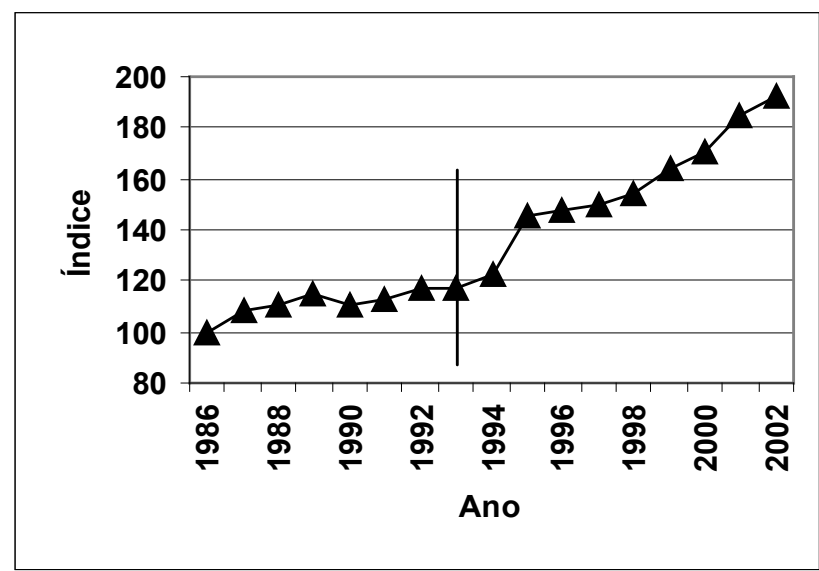

Fonte: Gasques et al. (2004).

GRÁFICO 14 - EVOLUÇÃO DA PARTICIPAÇÃO DA AGROPECUÁRIA BRASILEIRA NO EMPREGO - 1990 A 2003

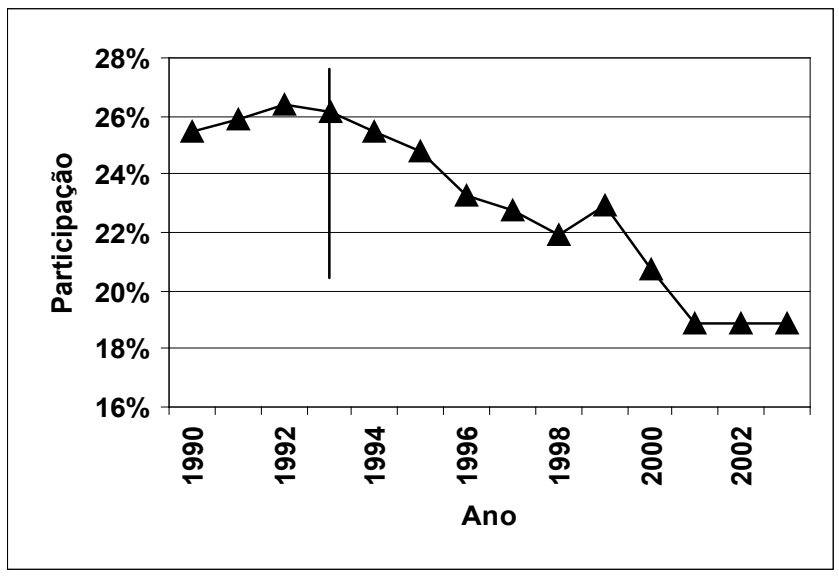

Fonte: IBGE (2005). 
Se nos últimos anos a participação da agropecuária no PIB é crescente e no emprego é decrescente, presume-se o crescimento da produtividade do trabalho neste setor. Gasques et al. (2004) confirmam esta tendência, que pode ser verificada no Gráfico 15.

GRÁFICO 15 - EVOLUÇÃO DA PRODUTIVIDADE DO TRABALHO NA AGROPECUÁRIA BR ASILEIRA - 1986 A 2002 (BASE $100=1986)$

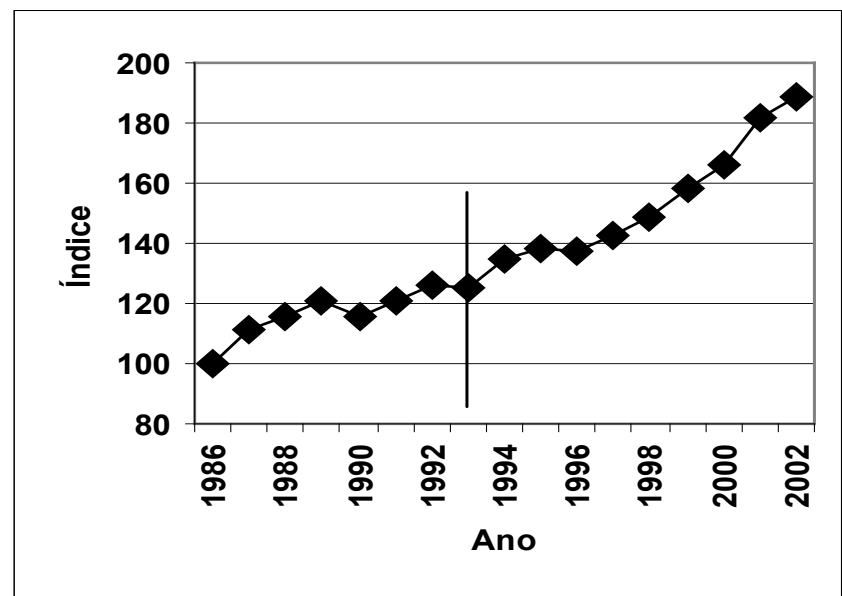

Fonte: Gasques et al. (2004).

A produtividade do trabalho na agropecuária brasileira cresceu a uma taxa geométrica de 2,8\% a.a. no período de 1986 a 1993 e de 4,4\% a.a. no período de 1993 a 2002. Este crescimento é resultado, possivelmente, do maior uso de máquinas e de insumos, aliado a técnicas mais eficientes de produção.

\subsection{Produtividade no Setor Industrial}

Utilizam-se dados de produtividade do setor industrial como uma proxy da produtividade do setor não-agropecuário.

O Gráfico 16 apresenta o índice de produtividade total dos fatores no setor industrial de 1986 a 2004. A PTF no setor industrial teve decréscimo anual de 0,79\% entre os anos de 1986 e 1993, e uma taxa geométrica anual de crescimento de 0,38\% entre os anos de 1993 e 2004 (calculado a partir de dados de BONELLI, 2001 e informações pessoais cedidas por Regis Bonelli). Embora a PTF no setor industrial tenha crescido de 1993 a 2004, ela cresceu menos que a PTF na agropecuária (que foi de $5,31 \%$ a.a. de 1993 a 2002). Essa diferença favorece o crescimento da participação da agropecuária no PIB. 
A produtividade do trabalho no setor industrial apresentou taxa geométrica de crescimento de 1,7\% a.a. para o período de 1986 a 1993 e de 3,1\% a.a. para ao período de 1993 a 2002 (segundo dados da produtividade do trabalho industrial do IBGE apresentados no Gráfico 17).

GRÁFICO 16 - EVOLUÇÃO DA PRODUTIVIDADE TOTAL DOS FATORES NA INDÚSTRIA BRASILEIRA - 1986 A 2004 (BASE 100 = 1986)

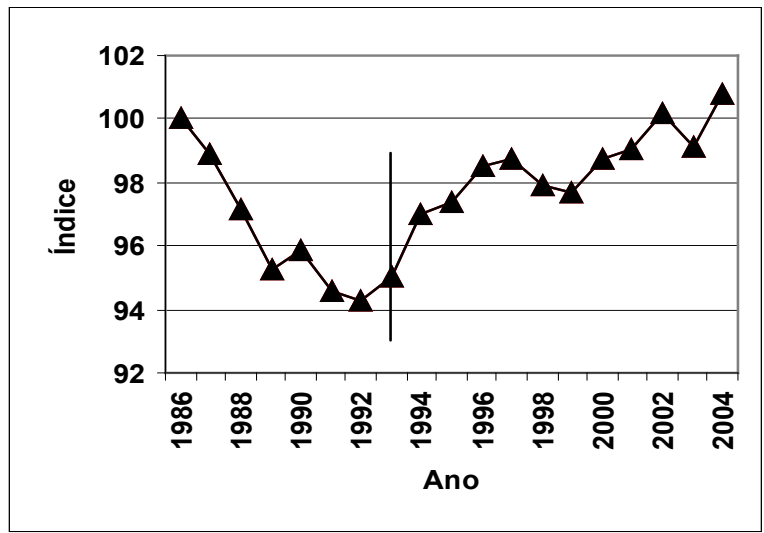

Fonte: Bonelli (2001) e Regis Bonelli (informações pessoais).

GRÁFICO 17 - EVOLUÇÃO DA PRODUTIVIDADE DO TRABALHO NO SETOR INDUSTRIAL BRASILEIRO - 1986 A 2002 (BASE $100=$ 1986)

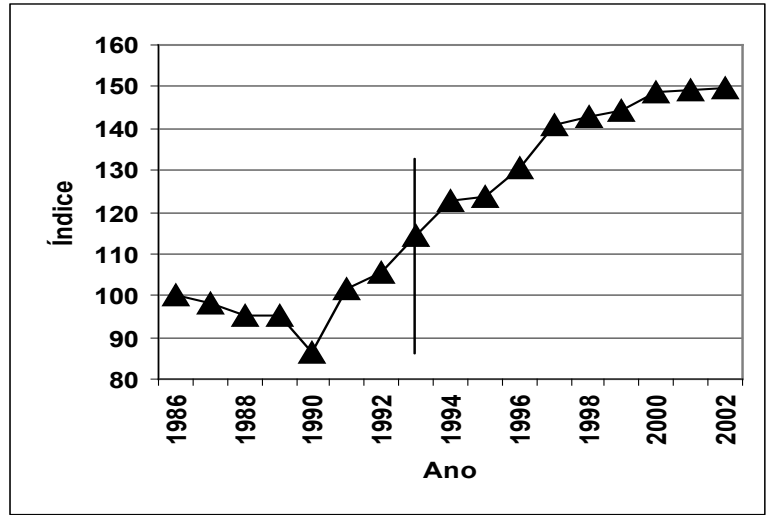

Fonte: IBGE (2005). 


\subsection{Análise Econométrica}

Para verificar estatisticamente a presença de "quebra" na tendência de evolução da participação da agropecuária no PIB brasileiro (Gráfico 4) utilizou-se um modelo com binária baseado em Hoffmann e Vieira (1987) e Greene (2003). De acordo com este modelo, tem-se "quebra" de tendência se o coeficiente associado à variável binária for estatisticamente diferente de zero. O modelo econométrico é:

$$
\mathrm{P}_{\mathrm{agr} j}=\alpha+\beta_{1} \cdot\left(\text { Ano }_{j}-K\right)+\mathrm{Z} \cdot \beta_{2} \cdot\left(\text { Ano }_{j}-K\right)+u_{j},
$$

Onde:

$P_{a g r j}=$ participação da agropecuária no PIB no ano $j$;

$\alpha=$ constante;

$K=$ ano da quebra (1993);

$u_{j}=$ resíduo da regressão; e

$Z=$ Binária.

$$
Z=\left\{\begin{array}{l}
0 \text { para Ano }<\text { K (1986 a 1992) } \\
1 \text { para Ano } \geq \text { K (1993 a 2004) }
\end{array}\right.
$$

Os dados utilizados para estimar as equações (5), (6) e (8) encontram-se na Tabela 1 (Anexo). Inicialmente, consideram-se os valores de $P_{\text {agr }}$ calculados usando a metodologia do SCN/Brasil/97.

O ajustamento econométrico da equação (6) foi realizado pelo método de Mínimos Quadrados Ordinários (MQO). O valor entre parênteses abaixo do coeficiente é a estatística " $t$ " " $a$ " indica nível de significância inferior a 1\%).

$$
\begin{gathered}
\text { Pagr }_{j}=6,7169-0,3765 \cdot\left(\text { Ano }_{j}-K\right)+Z \cdot 0,6291 \cdot\left(\text { Ano }_{j}-K\right)+u_{j}, \\
(14,23)^{\mathrm{a}} \quad(-3,42)^{\mathrm{a}} \quad(3,59)^{\mathrm{a}} \\
R^{2}=0,669 \quad n=19 \quad F=6,481^{\mathrm{a}} .
\end{gathered}
$$

Como pode ser verificado, o valor do teste " $t$ " para o coeficiente de $\beta_{2}$ é 3,59 , enquanto o valor " $t$ " crítico a $1 \%$ é de aproximadamente 2,86 . Portanto, rejeitase a hipótese $\mathrm{H}_{0}: \beta_{2}=0$ em favor da hipótese alternativa, em que há "quebra" de tendência. 
Verificada estatisticamente a "quebra" de tendência, ajustaram-se sete modelos com variáveis binárias para o período de 1986 a 2004 pelo método dos Mínimos Quadrados Ordinários (MQO). O modelo testado é:

$$
\begin{aligned}
\text { Pagr }_{j}= & a_{0}+a_{1} . \text { Prec/Ppag }+a_{2} . \text { PTagr }+a_{3} . \text { PTind }+Z+a_{4} . \text { Z.Prec/Ppag }+ \\
& +\mathrm{a}_{5} . \mathrm{Z} . \text { PTagr }+\mathrm{a}_{6} . \mathrm{Z} . \text { PTind }+\mathrm{U}_{\mathrm{j}}
\end{aligned}
$$

Onde:

Pagr = participação da agropecuária no PIB em \%;

Pagr/Pind = índice da relação de preços agropecuários/ preços industriais

Prec/Ppag = índice da relação de preços recebidos/ preços pagos (agropecuários e não-agropecuários) pelo setor agropecuário no estado de São Paulo;

PTagr = índice de produtividade do trabalho no setor agropecuário;

PTind = índice de produtividade do trabalho no setor Industrial;

$Z=$ variável binária que assume os seguintes valores:

$$
Z=\left\{\begin{array}{l}
0 \text { para Ano }<\text { K (1986 a 1992) } \\
1 \text { para Ano } \geq \text { K (1993 a 2004) }
\end{array}\right.
$$

Visando a melhoria das estimativas, algumas regressões incluíram Pagr ${ }_{t-1}$ como variável explicativa.

Em todos os modelos estimados, a variável dependente assumiu os valores observados enquanto as variáveis explicativas (inclusive a variável dependente defasada de 1 período como variável explicativa) assumiram valores em escala logarítmica. Os modelos estimados foram: (1) inclusão de variável binária para intercepto e multiplicada por Prec/Ppag, PTagr e PTind; (2) exclusão da variável PTind e inclusão de variável binária multiplicada por Prec/Ppag; (3) exclusão da variável PTind e inclusão das variáveis dependente defasada como explicativa e binária para intercepto; (4) inclusão de variável binária para intercepto e multiplicada por Prec/Ppag; (5) exclusão da variável PTind e inclusão das variáveis dependente defasada de 1 período como explicativa e binária multiplicada por Prec/Ppag; (6) exclusão da variável PTagr e inclusão da variável binária multiplicada por Prec/Ppag; e (7) exclusão da variável PTind e inclusão da variável binária para intercepto e multiplicada por Prec/Ppag.

Estes modelos não apresentaram resultados satisfatórios, apresentando em todos os casos coeficientes negativos para a variável Prec/Ppag, todos os coeficientes positivos para a variável PTind, e alguns coeficientes negativos para a variável PTagr, 
mostrando resultados divergentes do esperado pelo modelo contábil apresentado anteriormente. Estatisticamente, os modelos também não se mostraram satisfatórios, tanto com relação à estatística $t$ (significância de cada coeficiente) e à estatística Durbin-Watson $(D W)$, que revelou autocorrelação positiva ou região de indecisão (ver Quadro 1 - Anexo).

Dessa forma, foram ajustados 12 outros modelos econométricos, também pelo método MQO, mas se restringindo ao período de 1993 a 2004 a fim de estimar a equação (5) do item 5.1. Os modelos são: (1) variáveis normais (observados); (2) variáveis normais e ausência da variável PTind; (3) variáveis normais, ausência da variável PTind e inclusão da variável Tempo (Ano); (4) variáveis em logaritmo neperiano $(L N)$ e variável Tempo em valor observado; (5) variáveis em $L N$ e variável Tempo em valor observado e exclusão da variável PTind; (6) todas as variáveis em $L N$ e inclusão da variável dependente defasada de 1 período como variável explicativa; (7) todas as variáveis em $L N$, inclusão da variável dependente defasada de 1 período como variável explicativa e exclusão da variável PTind; (8) variáveis explicativas e a variável dependente defasada em $L N$ (variável dependente em valor observado); (9) variáveis explicativas e a variável dependente defasada em $L N$ (variável dependente em valor observado) e exclusão da variável Pagr/Pind; (10) variáveis explicativas e a variável dependente defasada em $L N$ (variável dependente em valor observado) e exclusão da variável Prec/Ppag; (11) variáveis explicativas e defasada em $L N$ e substituição da variável Prec/Ppag pela variável Prec ${ }_{t} /$ Ppag $\left._{(t-1)}\right)^{8}$; e (12) variáveis explicativas e defasada em $L N$, exclusão da variável PTind e substituição da variável Prec/Ppag pela variável Prec t / Ppag (t-1). (ver Quadro 2 no Anexo9).

Verifica-se que os modelos ajustados apresentam coeficientes de determinação $\left(R^{2}\right)$ e estatística $F$ de significação satisfatórios, que revelam a significância aceitável dos modelos. Os modelos sem a variável dependente defasada como variável explicativa apresentam estatística $D W$ em níveis que revelam autocorrelação positiva ou região de indecisão. Alguns modelos apresentam os sinais dos coeficientes das variáveis que representam os índices de preços agropecuários versus industriais ao contrário do esperado pelo modelo teórico. Uma explicação possível para esse resultado é a ocorrência de elevado índice de correlação entre as duas relações de preços que são

8 Em função de os produtores agropecuários receberem pela produção no período $t$ (preços recebidos) e adquirirem os insumos no período ( $t-1)$ (preços pagos).

9 Na presença de variável dependente defasada como explicativa faz-se uso do teste $h$ de Durbin, definido pela seguinte fórmula:,

$h \cong(1-0,5 d) \sqrt{\frac{n}{1-n[\operatorname{var}(\hat{\alpha})]}}$

onde $d$ é a estatística Durbin-Watson, $n$ o número de observações e var $(\hat{\alpha})$ é a variância do coeficiente da variável defasada. Como o denominador da raiz pode ser um número negativo, em alguns casos a estatística $b$ Durbin torna-se incalculável. 
utilizadas nos modelos (Prec/Ppag e Pagr/Pind), gerando problema de multicolinearidade, pois quando da exclusão de uma variável de preços relativos, esse problema é solucionado (passagem do modelo 8 para o 9 e o 10). Percebe-se também que, ao se excluir a variável Pagr/Pind (modelo 9), os resultados são melhores se comparado com o modelo que exclui a variável Prec/Ppag (modelo 10).

Os modelos que apresentam a variável $\operatorname{Prec}_{t} / \operatorname{Ppag}_{t-1}$ não apresentaram bons níveis de significância estatística, além de alguns sinais de coeficientes serem ao contrário do esperado pelo modelo teórico.

A melhor equação estimada, do ponto de vista econométrico, é a de número 9, reproduzida abaixo. $\mathrm{O}$ valor entre parênteses abaixo do coeficiente é a estatística " $t$ " " $a "$ indica nível de significância inferior a $1 \%, " b$ " indica nível de significância inferior a $5 \%$ e "c" indica nível de significância inferior ou igual a 10\%). Abaixo da estatística " $t$ " é apresentada a elasticidade da variável Pagr em relação a cada variável explicativa. Essas elasticidades foram calculadas com base no valor médio da variável dependente. ${ }^{10}$

\begin{tabular}{|c|c|c|c|c|}
\hline$(-1,189)$ & $(2,833)^{b}$ & $(1,891)^{c}$ & $(-2,054)^{c}$ & $(2,196)^{c}$ \\
\hline elasticidade & 1,1334 & 0,6155 & $-1,3780$ & 0,5388 \\
\hline
\end{tabular}

$R^{2}=0,7577 \quad n=12 \quad F=4,474^{b} \quad h$-Durbin $=$ incalculável

A equação acima apresenta todos os coeficientes com os sinais esperados. Considerando a elasticidade, as principais variáveis determinantes da Pagr são (em ordem decrescente): PTind, Prec/Ppag, PTagr e Pagr $r_{t-1}$.

Alternativamente, pode-se considerar a nova série de Pagr definida pela metodologia do SCN/Brasil/07 (terceira coluna da Tabela 1 no Anexo). Essa nova série só existe para 1995 a 2006 e mostra a mesma sazonalidade e tendência para dado similar da série definida pela metodologia SCN/Brasil/97. O uso dessa nova série implica: (1) considerar os dados da série SCN/Brasil/97 até 1994 e os dados novos da série SCN/Brasil/2007, o que não é tão bom quanto usar apenas a série completa do SCN/Brasil/97 que segue a mesma metodologia de cálculo; (2) interpolar o dado de 1994 como sendo a média do dado de 1993 e o de 1995; (3) considerar apenas a série de dados de 1995 a 2004, o que gera menos observações em relação aos casos anteriores. As regressões com essas três opções estão na última página do Anexo

10 Alternativamente, pode-se calcular as elasticidades considerando o valor ano a ano da variável dependente. Assim, surgem elasticidades ponto a ponto. Os valores das elasticidades de Pagr em relação a Prec/Ppag, PTagr, PTind e Pagr t-1 calculadas como a média das elasticidades ponto a ponto são, respectivamente, $1,1508,0,625,-1,3992$ e 0,5471 . Observa-se que esses novos valores não alteram a ordem de importância das variáveis explicativas em relação aos valores das elasticidades mostradas na equação (9). 
e, ao compará-las com a expressão (9) acima, observa-se que os sinais das variáveis explicativas se mantêm os mesmos, mudando apenas os valores das elasticidades.

\section{CONSIDERAÇÕES FINAIS}

Ao contrário do comportamento da maioria dos países e ao que prevê a literatura sobre o assunto, a agropecuária brasileira aumentou sua participação na geração do PIB do Brasil de meados dos anos 90 a 2004.

A produção brasileira de carnes cresceu devido ao aumento do rendimento de carcaça por animal e, principalmente, ao crescimento do número de animais abatidos, destacando-se o abate de aves, que cresceu $189 \%$ de 1993 a 2004. A produção agrícola também aumentou a partir de 1994 devido, principalmente, ao crescimento em área plantada e ganhos de produtividade.

Verificou-se, também, crescimento da produtividade total dos fatores e da produtividade do trabalho na agropecuária, assim como a redução da participação deste setor na geração de emprego. As regressões para o período de 1993 a 2004 confirmam que o crescimento da produtividade do trabalho no setor agropecuário contribuiu para o crescimento da participação da agropecuária no PIB brasileiro.

Foi visto que a produtividade total dos fatores no setor industrial decresceu no período de 1986 a 1992 e apresentou crescimento a partir de 1993, porém um crescimento inferior ao da agropecuária.

O modelo econométrico utilizado confirmou estatisticamente a "quebra" da tendência de evolução da participação da agropecuária no PIB brasileiro em 1993, que já havia sido observada graficamente.

O modelo econométrico ajustado com os valores das variáveis explicativas e defasada em $L N$ (variável dependente em valor observado, modelo semi- $L N$ ) e exclusão da variável relação de preços agropecuários/ preços industriais apresentou os melhores resultados estatísticos, apresentando bons níveis de significância e os sinais dos coeficientes de acordo com os esperados pelo modelo teórico. Os demais modelos estimados também destacam que ganhos em termos de trocas resultam em elevado crescimento na participação da agropecuária no PIB. O crescimento da produtividade do setor industrial também é bastante importante na explicação da participação da agropecuária no PIB, porém, contribuindo para sua redução. De acordo com os resultados, a baixa performance da produtividade industrial em relação ao compor- 
tamento da produtividade da agropecuária no período de 1993 a 2004, contribuiu para o crescimento da participação da agropecuária no PIB do Brasil.

Os resultados econométricos são adequados para analisar a contribuição da agropecuária para o PIB do Brasil após 2004. Informações preliminares da participação da agropecuária no PIB do Brasil indicam redução para $8 \%$ em 2005, menor que os 9,7\% ocorridos em 2004 (de acordo com os dados gerados com o SCN/Brasil/97). Tanto produtores rurais quanto órgãos governamentais apresentaram a redução da razão de preços recebidos/ preços pagos pela agropecuária, causada pela forte apreciação da taxa de câmbio, como a principal responsável pela redução da participação da agropecuária no PIB. Isto é coerente com a equação estimada, pois a redução de $1 \%$ na relação de preços recebidos/ preços pagos pela agropecuária gera uma redução de 1,1334\% na participação da agropecuária no PIB.

Como sugestão para futuros trabalhos, é importante testar a equação (5) para outros países, comparando seus resultados com o do Brasil.

\section{REFERENCIAS}

AHUMADA, J. Teoria y programación del desarrolo economico. Santiago: Ilpes, 1967. $62 \mathrm{p}$.

ALVES, A.F. Contribuição da agricultura ao crescimento econômico: o excedente financeiro de 1980 a 1998. Piracicaba, ESALQ/USP, 2000. 127 p.

ARAÚJO, P.F.C. Agricultura no processo de desenvolvimento econômico. In: ARAÚJO, P.F.C.; SCHUH, G. E. Desenvolvimento da agricultura. São Paulo: Editora Pioneira, 1975. v. 1, p. 83-97.

; SCHUH, G.E. Desenvolvimento econômico e agricultura. In: BARROS, G.S; AMARAL, C.M.; ARAÚJO, P.F.C. de; SCHUH, G.E. Fundamentos de economia agricola. Piracicaba: FEALQ, fev. 1988, p. 227-277.

BACHA, C. J. C. Economia e política agricola no Brasil. São Paulo: Atlas, 2004. 226 p.

BACHA, C. J. C.; ROCHA, M.T. O comportamento da agropecuária brasileira no período de 1987 a 1996. Revista de Economia e Sociologia Rural, Brasília. v. 36, n. l, p. 35-59, jan./mar. 1998.

. Evolução da participação da agropecuária no PIB brasileiro nas últimas três décadas. In: ENCONTRO DOS ECONOMISTAS DE LÍNGUA PORTUGUESA, 4, 2001. Évora. Disponível em: <www.nuca.ie.ufrj.br/infosucro/biblioteca/economiabrasileira/bacha_evolucao.doc>. Acesso em: 20 set. 2005.

BACHA, C.J.C. Entendendo a Economia Brasileira. Campinas: Editora Aliena, 2007. 
BAER, W. The Brazilian economy: growth and development, 5.ed. Westport: Praeger Publishers, 2001. 499 p.

BARROS, A. L. M. de. Capital, produtividade e crescimento da agricultura: o Brasil de 1970 a 1995. 1999, 149 p. Tese (Doutorado em Ciências; área de concentração em Economia Aplicada) - Escola Superior de Agricultura "Luiz de Queiroz", Universidade de São Paulo. Piracicaba.

BONELLI, R. Produtividade total dos fatores (PTF) e o produto potencial da economia brasileira: uma nota. São Paulo, IPEA. 2001. 2 p. (Boletim Conjuntural, 53)

Industrialização e desenvolvimento: notas e conjecturas com foco na experiência do Brasil. Disponível em: <http:// www.ecostrat.com.br >. Acesso em: 10 dez. 2005.

FUNDAÇÃO GETULIO VARGAS. FGV dados. Disponível em: < http://www. fgvdados.com.br>. Acesso em: 25 nov. 2005.

FURTUOSO, M.C.O.; GUILHOTO, J.J.M. Estimativa e mensuração do produto interno bruto do agronegócio, 1994 a 2000. Revista de Economia e Sociologia Rural, Brasília, v. 41, n. 4, p. 803-827, out./dez. 2003. Disponível em: < http:// www.scielo.br>. Acesso em: 10 dez. 2005.

GASQUES, J.G.; BASTOS, E.T.; BACCHI, M.R.P.; CONCEIÇÃO, J.C.P.R. da. Condicionantes da produtividade da agropecuária brasileira. Brasília: IPEA, 2004. 31 p. (Texto para discussão, 1017).

GREENE, W.H. Econometric Analysis, 5.ed. Upper Saddle River: Prentice Hall, 2003. 1026 p.

GUILHOTO, J.J.M. Regional importance of the agribusiness in the Brazilian economy. In: CONGRESS OF THE EUROPEAN REGIONAL SCIENCE ASSOCIATION, 44, Porto. 2004. I CD-ROM.

GUJARATI, D.N. Econometria básica. 3.ed. São Paulo: Makron Books, 2000. 846 p.

HOFFMANN, R.; VIEIRA, S. Análise de regressãa, uma introdução à econometria. São Paulo: HUCITEC, 1987. 378 p.

INSTITUTO BRASILEIRO DE GEOGRAFIA E ESTATÍSTICA - IBGE. Ammário Estatístico do Brasil, 1987-1989, 1991-1993. . Anuário Estatístico do Brasil, 1995-2001, 2003 (CD-ROM).

. Sistema SIDRA. Disponível em: < http://www.ibge.gov.br>. Acesso em: 5 dez. 2005.

REGUNAGA, M. Issues in agricultural trade: the Americas. Disponível em: < http:// www.agritrade.org >. Acesso em: 18 nov. 2005.

ROSSI JÚNIOR, J.L.; FERREIRA, P.C. Evolução da produtividade industrial brasileira e abertura comercial. Rio de Janeiro: IPEA, 1999, 31.p. (Texto para discussão, $651)$. 
SCHULTZ, T.W. The declining economic importance of agricultural land. The Economic Journal, London, v. 61, n. 244, p. 725-740, dez. 1951. Disponível em: $<$ http://www.jstor.org >. Acesso em: 15 nov. 2005.

STERN, N. Growth theories, old and new, and the role of agriculture in economic development. London: Suntory-Toyota International Centre for Economic and Related Disciplines/London School of Economics, 1994. 148 p.

WORLD BANK. World development indicators. 2000. CD-ROM . World development indicators. 2005. CD-ROM

. World development indicators. 2007. Homepage http://www.worldbank.org (Acesso em: 09 ago.2007).

ANEXO

TABELA I - DADOS UTILIZADOS NAS REGRESSÕES DO BRASIL

\begin{tabular}{rcccccc}
\hline & \multicolumn{2}{c}{ Pagr (\%) } & Prec/Ppag & Pagr/Pind & PTagr & PTind \\
\cline { 2 - 3 } & SCN/Brasil/97 & SCN/Brasil/07 & & & & \\
\hline 1986 & 11,20 & & 41,98 & 73,83 & 74,04 & 81,38 \\
1987 & 9,30 & 42,57 & 65,81 & 82,15 & 79,78 \\
1988 & 9,80 & 43,93 & 58,65 & 85,36 & 77,57 \\
1989 & 7,70 & 50,28 & 66,25 & 89,39 & 77,50 \\
1990 & 6,92 & 50,28 & 65,17 & 85,80 & 70,41 \\
1991 & 6,90 & 53,05 & 90,48 & 89,55 & 82,81 \\
1992 & 6,23 & 55,61 & 64,08 & 93,66 & 85,90 \\
1993 & 5,77 & 70,47 & 65,27 & 92,44 & 92,97 \\
1994 & 8,63 & & 93,51 & 88,63 & 100,00 & 100,00 \\
1995 & 8,47 & 83,25 & 99,98 & 102,14 & 100,56 \\
1996 & 7,90 & & 80,57 & 99,36 & 101,95 & 106,10 \\
1997 & 7,57 & 90,00 & 110,47 & 105,47 & 114,59 \\
1998 & 7,83 & 5,8 & 95,18 & 117,38 & 109,84 & 116,38 \\
1999 & 7,90 & 5,5 & 85,53 & 118,58 & 117,24 & 117,60 \\
2000 & 7,70 & 5,4 & 90,74 & 123,11 & 123,21 & 121,03 \\
2001 & 8,00 & 5,5 & 96,41 & 129,85 & 134,33 & 121,30 \\
2002 & 8,20 & 5,5 & 93,39 & 137,05 & 139,63 & 121,73 \\
2003 & 9,40 & 5,6 & 96,95 & 142,56 & 145,84 & 125,49 \\
2004 & 9,65 & 6,0 & 90,29 & 134,69 & 152,33 & 129,37 \\
\hline
\end{tabular}

Fonte: IBGE (2005), Bacha (2007), FGV (2005) e Gasques et al. (2004).

Notas: Pagr $=$ participação da agropecuária no PIB em \%; Pagr/Pind $=$ índice da relação de preços agropecuários/ preços industriais (base $100=$ agosto de 1994); Prec/Ppag = índice da relação de preços recebidos/ preços pagos (agropecuários e não-agropecuários) pelo setor agropecuário no Estado de São Paulo (base 100 = agosto de 1994); PTagr = índice de produtividade do trabalho no setor agropecuário (base $100=1994) ;$ PTind $=$ índice de produtividade do trabalho no setor industrial (base $100=1994$ ); 


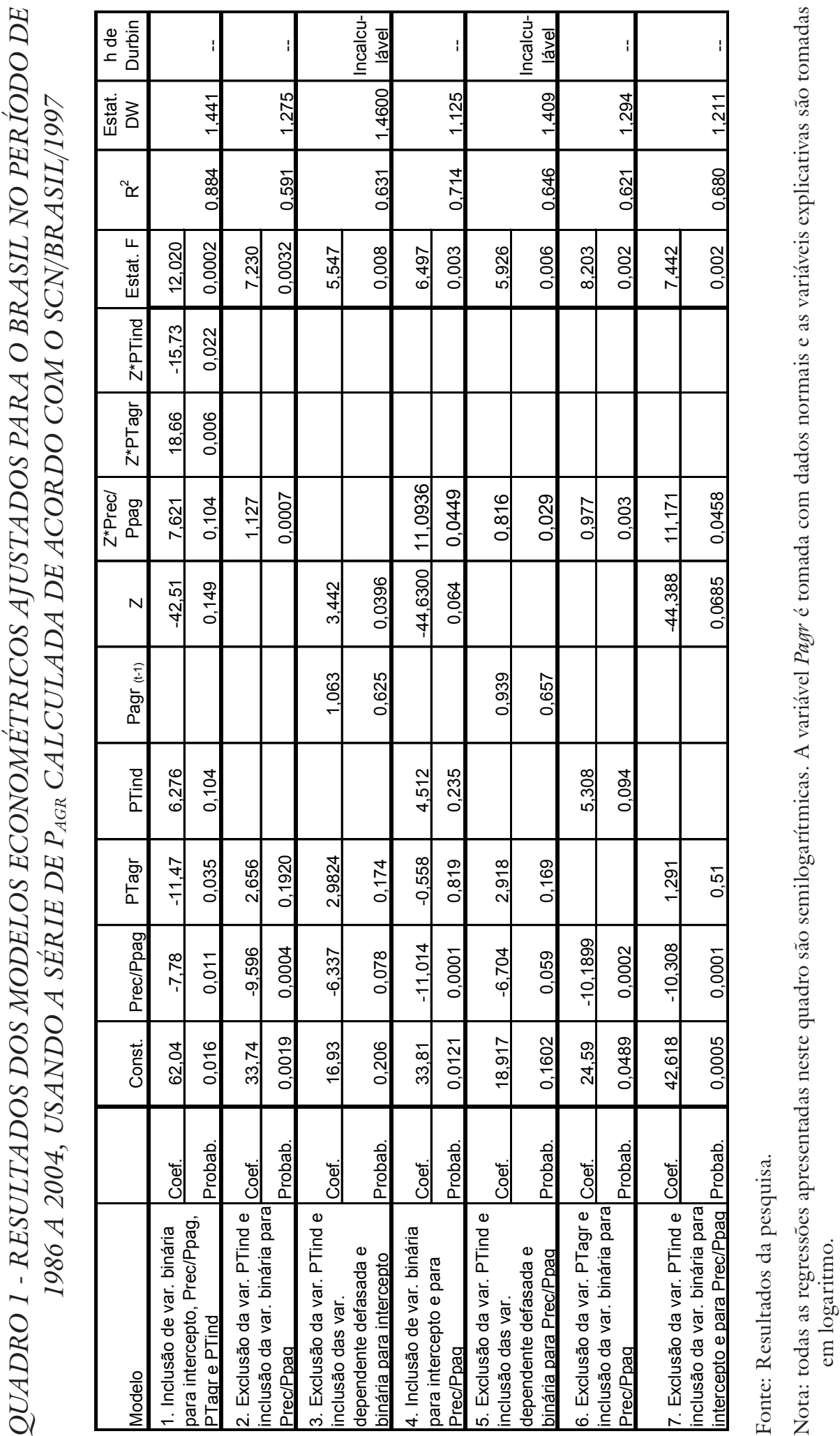




\section{QUADRO 2 - RESULTADOS DOS MODELOS ECONOMÉTRICOS AJUS- TADOS PARA O BRASIL NO PERÍODO DE 1993 A 2004,"11 USANDO A SÉRIE DE PAGR CALCULADA DE ACORDO COM O SCN/BR ASIL/1997}

\begin{tabular}{|c|c|c|c|c|c|c|c|c|c|c|c|c|c|}
\hline Modelos & & Const. & Prec/Ppag & $\begin{array}{l}\text { Prec }_{t} / \\
\text { Ppag }_{(t-1)} \\
\end{array}$ & Pagr/Pind & PTagr & PTind & Pagr $_{(t-1)}$ & Tempo & $\begin{array}{c}\text { Estat. } \\
\mathrm{F}\end{array}$ & $\mathrm{R}^{2}$ & $\begin{array}{l}\text { Estat. } \\
\text { DW }\end{array}$ & $\begin{array}{c}\mathrm{h} \text { de } \\
\text { Durbin }\end{array}$ \\
\hline \multirow[b]{2}{*}{ 1. Variáveis normais } & Coef. & 5,275 & 0,0497 & & 0,0262 & 0,0323 & $-0,0738$ & & & 2.619 & \multirow[b]{2}{*}{0,599} & \multirow[b]{2}{*}{1,084} & \multirow[b]{2}{*}{-} \\
\hline & Probab. & 0,3915 & 0,3548 & & 0,5809 & 0,3105 & 0,3677 & & & 0,126 & & & \\
\hline \multirow{2}{*}{$\begin{array}{l}\text { 2. Variáveis normais e } \\
\text { ausência da var. } \\
\text { PTind }\end{array}$} & Coef. & 0,8149 & 0,0554 & & $-0,005165$ & 0,0247 & & & & 3,212 & \multirow[b]{2}{*}{0,546} & \multirow[b]{2}{*}{1,061} & \multirow[b]{2}{*}{-} \\
\hline & Probab. & 0,8185 & 0,2959 & & 0,8728 & 0,4081 & & & & 0,083 & & & \\
\hline \multirow{2}{*}{$\begin{array}{l}\text { 3. Variáveis normais, } \\
\text { ausência de Ptind e } \\
\text { inclusão da var. } \\
\text { Tempo }\end{array}$} & Coef. & 1585,3 & 0,0111 & & 0,0595 & 0,1104 & & & $-0,7996$ & 3,244 & \multirow[b]{2}{*}{0,649} & \multirow[b]{2}{*}{1,126} & \multirow[b]{2}{*}{-} \\
\hline & Probab. & 0,1941 & 0,8477 & & 0,305 & 0,135 & & & 0,1943 & 0,083 & & & \\
\hline \multirow{2}{*}{$\begin{array}{l}\text { 4. Variáveis em LN, } \\
\text { var. Tempo em } \\
\text { valores obsevados }\end{array}$} & Coef. & 198,61 & 0,0351 & & 0,7443 & 1,8857 & $-0,0565$ & & $-0,105$ & 2,720 & \multirow[b]{2}{*}{0,694} & \multirow[b]{2}{*}{1,042} & \multirow[b]{2}{*}{-} \\
\hline & Probab. & 0,6010 & 0,9716 & & 0,2218 & 0,5145 & 0,9847 & & 0,6046 & 0,128 & & & \\
\hline \multirow{2}{*}{$\begin{array}{l}\text { 5. Variáveis em LN, } \\
\text { var. Tempo em } \\
\text { valores observados e } \\
\text { ausência da var. Ptinc }\end{array}$} & Coef. & 205,255 & 0,0214 & & 0,7446 & 1,9341 & & & $-0,1081$ & 3,966 & \multirow[b]{2}{*}{0,694} & \multirow[b]{2}{*}{1,041} & \multirow[b]{2}{*}{--} \\
\hline & Probab. & 0,1513 & 0,9727 & & 0,1842 & 0,1383 & & & 0,1482 & 0,054 & & & \\
\hline \multirow{2}{*}{$\begin{array}{l}\text { 6. Variáveis em LN e } \\
\text { inclusão da } \\
\text { var. dependente } \\
\text { defasada }\end{array}$} & Coef. & $-2,5931$ & 1,5842 & & $-0,2966$ & 0,5925 & $-1,1356$ & 0,7436 & & 4,489 & \multirow[b]{2}{*}{0,789} & \multirow[b]{2}{*}{2,109} & \multirow[b]{2}{*}{$-0,1710$} \\
\hline & Probab. & 0,52 & 0,0897 & & 0,6816 & 0,1588 & 0,2558 & 0,1267 & & 0,048 & & & \\
\hline \multirow{2}{*}{$\begin{array}{l}\text { 7. Variáveis em LN, } \\
\text { inclusão da } \\
\text { var. dependente } \\
\text { defasada e exclusão } \\
\text { da var. PTind }\end{array}$} & Coef. & $-6,0645$ & 1,838 & & $-0,8201$ & 0,4227 & & 0,8598 & & 4,819 & \multirow[b]{2}{*}{0,734} & \multirow[b]{2}{*}{2,030} & \multirow[b]{2}{*}{$-0,046$} \\
\hline & Probab. & 0,0601 & 0,0524 & & 0,1935 & 0,2744 & & 0,0832 & & 0,035 & & & \\
\hline \multirow{2}{*}{$\begin{array}{l}\text { 8. Variáveis } \\
\text { explicativas e } \\
\text { dependente defasada } \\
\text { em LN (var. } \\
\text { dependente em valor } \\
\text { observado) } \\
\end{array}$} & Coef. & $-31,2022$ & 12,5785 & & $-3,5849$ & 5,5891 & $-8,2916$ & 6,0578 & & 4,116 & \multirow[b]{2}{*}{0,774} & & \\
\hline & Probab. & 0,336 & 0,0872 & & 0,5323 & 0,1018 & 0,2876 & 0,1159 & & 0,057 & & 2,021 & $\begin{array}{c}\text { Incalcu- } \\
\text { lável }\end{array}$ \\
\hline $\begin{array}{l}\text { 9. Var. explicativas e } \\
\text { dependente defasada }\end{array}$ & Coef. & $-12,9096$ & 9,1633 & & & 4,9761 & $-11,141$ & 4,3565 & & 4,474 & & & \\
\hline $\begin{array}{l}\text { em LN e exclusão da } \\
\text { var. Pagr/Pind }\end{array}$ & Probab. & 0,273 & 0,0253 & & & 0,1005 & 0,0791 & 0,0641 & & 0,026 & 0,758 & 1,724 & $\begin{array}{c}\text { Incalcu- } \\
\text { lável }\end{array}$ \\
\hline 10. Var. explicativas e & Coef. & 18,9943 & & & 5,66145 & 3,8055 & $-12,033$ & 0,5838 & & 2,824 & & & \\
\hline $\begin{array}{l}\text { em LN e exclusão da } \\
\text { var. Prec/Ppag }\end{array}$ & Probab. & 0,3825 & & & 0,1569 & 0,2903 & 0,1893 & 0,8081 & & 0,110 & 0,617 & 1,569 & $\begin{array}{c}\text { Incalcu- } \\
\text { lável }\end{array}$ \\
\hline $\begin{array}{l}\text { 11. Variáveis } \\
\text { explicativas em LN e }\end{array}$ & Coef. & $-31,0999$ & & 5,469 & & $-0,708$ & 3,506 & 1,469 & & 2,071 & & & \\
\hline $\begin{array}{l}\text { utilização da var. } \\
\text { Prec / Ppag }_{(t-1)}\end{array}$ & Probab. & 0,3337 & & 0,3628 & & 0,9156 & 0,6957 & 0,5633 & & 0,188 & 0,542 & 1,845 & $\begin{array}{c}\text { Incalcu- } \\
\text { lável } \\
\end{array}$ \\
\hline $\begin{array}{l}\text { 12. Variáveis } \\
\text { explicativas em LN, }\end{array}$ & Coef. & $-19,945$ & & 3,862 & & 1,7206 & & 1,7677 & & 3,021 & & & \\
\hline $\begin{array}{l}\text { excusao da var. } \\
\text { PTind e utilização da } \\
\text { var. Prec } t / \text { ppag }_{(t-1)}\end{array}$ & Probab. & 0, & & 0,3378 & & 0,4789 & & 0,4419 & & 94 & 31 & 1.936 & $\begin{array}{c}\text { Incalcu- } \\
\text { lável } \\
\end{array}$ \\
\hline
\end{tabular}

Fonte: Resultados da pesquisa.

11 Os modelos 9, 10, 11 e 12 utilizam a variável dependente em valor observado. No caso de haver variável dependente defasada como explicativa, esta se encontra em LN. 
Estimativas alternativas da equação (9) combinando dados de Pagr da série definida pelo SCN/Brasil/1997 com a da série SCN/Brasil/2007 ou usando apenas a série SCN/Brasil/2007 (dados da Tabela 1)

Regressão usando Pagr de 1993 e 1994 da série SCN/Brasil/1997 e dados de 1995 a 2004 da série SCN/Brasil/2007

$$
\begin{aligned}
& \text { Pagr }=16,597+8,891 \cdot \mathrm{LN}(\text { Prec/Ppag })+9,869 \cdot \mathrm{LN}(\text { PTagr })-20,210 \cdot \mathrm{LN}(\text { PTind }) \quad-0,911 \cdot \mathrm{LN}\left(\text { Pagr }_{t-1}\right) \\
& (1,018) \quad(2,688)^{\mathrm{b}} \quad(2,627)^{\mathrm{b}} \quad(-3,201)^{\mathrm{b}} \quad(-0,489) \\
& \begin{array}{lllll}
\text { elasticidade } & 1,4302 & 1,5875 & -3,2508 & -0,1466
\end{array}
\end{aligned}
$$

$R^{2}=0,6917 \quad n=12 \quad F=3,926^{\mathrm{c}} \quad h$-Durbin $=$ incalculável

Regressão usando Pagr de 1993 da série SCN/Brasil/1997 e dados de 1995 a 2004 da série SCN/Brasil/2007, com o valor de 1994 sendo uma interpolação entre as duas séries

\begin{tabular}{ccccc} 
Pagr $=-5,907$ & $+1,947 \cdot \mathrm{LN}($ Prec/Ppag $)$ & $+3,933 \cdot \mathrm{LN}($ PTagr $)$ & $-4,549 \cdot \mathrm{LN}($ PTind $)$ & $+3,349 \cdot \mathrm{LN}\left(\right.$ Pagr $\left._{t-1}\right)$ \\
$(-0,943)$ & $(1,510)$ & $(2,432)^{\mathrm{b}}$ & $(-2,062)^{\mathrm{c}}$ & $(2,512)^{\mathrm{b}}$ \\
elasticidade & 0,3256 & 0,6575 & $-0,7607$ & 0,5599 \\
$R^{2}=0,9083$ & $n=12 \quad F=17,344^{\mathrm{a}}$ & \multicolumn{3}{c}{ h-Durbin $=$ incalculável }
\end{tabular}

Regressão usando Pagr de 1993 da série SCN/Brasil/1997 e dados de 1995 a 2004 da série SCN/Brasil/2007, excluindo a informação de 1994

\begin{tabular}{ccccc} 
Pagr $=-6,892$ & $+3,912 \cdot \mathrm{LN}($ Prec/Ppag $)$ & $+3,684 \cdot \mathrm{LN}($ PTagr $)$ & $-6,190 \cdot \mathrm{LN}($ PTind $)$ & $+4,008 \cdot \mathrm{LN}\left(\right.$ Pagr $\left._{t-1}\right)$ \\
$(-1,145)$ & $(1,992)^{\mathrm{c}}$ & $(2,370)^{\mathrm{d}}$ & $(-2,539)^{\mathrm{b}}$ & $(2,918)^{\mathrm{b}}$ \\
elasticidade & 0,6523 & 0,6144 & $-1,0322$ & 0,6683 \\
$R^{2}=0,9276$ & $n=11$ & $F=19,208^{\mathrm{a}}$ & \multicolumn{3}{c}{ h-Durbin = incalculável }
\end{tabular}

Regressão usando dados de 1995 a 2004 de Pagr da série SCN/Brasil/2007

$\begin{array}{ccccc}\text { Pagr }=-9,69+ & 4,229 \cdot \mathrm{LN}(\text { Prec/Ppag })+3,522 \cdot \mathrm{LN}(\text { PTagr }) & -5,713 \cdot \mathrm{LN}(\text { PTind }) & +3,935 \cdot \mathrm{LN}\left(\text { Pagr }_{t-1}\right) \\ (-1,123) & (1,869) & (2,050)^{\mathrm{c}} & (-2,076)^{\mathrm{c}} & (2,654)^{\mathrm{b}} \\ \text { elasticidade } & 0,7025 & 0,5850 & -0,9490 & 0,6537\end{array}$

$R^{2}=0,9287 \quad n=10 \quad F=16,285^{\text {a }} \quad h$-Durbin $=$ incalculável

O valor entre parênteses abaixo do coeficiente é a estatística " $t$ " " $a$ " indica nível de significância inferior a $1 \%$, " $b$ " indica nível de significância inferior a $5 \%$ e " $c$ " indica nível de significância inferior ou igual a 10\%). Abaixo da estatística " "é apresentada a elasticidade da variável Pagr em relação a cada variável explicativa. Essas elasticidades foram calculadas com base no valor médio da variável dependente. 